\title{
On the Optimal Provision of Social Insurance* Progressive Taxation versus Education Subsidies in General Equilibrium
}

\author{
Dirk Krueger $^{\dagger}$ \\ University of Pennsylvania, CEPR and NBER \\ Alexander Ludwig \\ SAFE at Goethe University Frankfurt, CMR and MEA
}

November 13, 2015

\begin{abstract}
In this paper we compute the optimal tax and education policy transition in an economy where progressive taxes provide social insurance against idiosyncratic wage risk, but distort the education decision of households. Optimally chosen tertiary education subsidies mitigate these distortions. We highlight the quantitative importance of general equilibrium feedback effects from policies to relative wages of skilled and unskilled workers: subsidizing higher education increases the share of workers with a college degree thereby reducing the college wage premium which has important redistributive benefits. We also argue that a full characterization of the transition path is crucial for policy evaluation. We find that optimal education policies are always characterized by generous tuition subsidies, but the optimal degree of income tax progressivity depends crucially on whether transitional costs of policies are explicitly taken into account and how strongly the college premium responds to policy changes in general equilibrium.

Keywords: Progressive Taxation, Education Subsidy, Transitional Dynamics

J.E.L. classification codes: E62, H21, H24
\end{abstract}

\footnotetext{
*We thank Felicia Ionescu, Costas Meghir, Dominik Sachs and Gianluca Violante for helpful discussions and seminar participants at various institutions and conferences for many useful comments. Krueger gratefully acknowledges financial support from the NSF under grant SES-0820494. Ludwig gratefully acknowledges financial support by the Research Center SAFE, funded by the State of Hessen initiative for research LOEWE.

${ }^{\dagger}$ Corresponding author. Department of Economics; University of Pennsylvania; 3718 Locust Walk; Philadelphia, PA 19104, USA; dkrueger@econ.upenn.edu
} 


\section{Introduction}

In the presence of uninsurable idiosyncratic earnings risk, progressive taxation provides valuable social insurance among ex ante identical households. In addition it might enhance equity among ex ante heterogeneous households, which is beneficial if the social welfare function used to aggregate lifetime utilities values such equity. However, if high-earnings households face higher average tax rates than low-earnings households, this might discourage the incentives of these households to become earningsrich through making conscious human capital accumulation decisions. The resulting skill distribution in the economy worsens, and aggregate economic activity might be depressed through this channel, which compounds the potentially adverse impact of progressive taxes on production through the classic labor supply channel.

In this paper we compute the optimal tax and education policy transition, within a simple parametric class, in an economy where progressive taxes provide social insurance against idiosyncratic wage risk, but distort the education decision of households. Optimally chosen tertiary education subsidies mitigate these distortions, making both policies potentially complementary. We model two different channels through which academic talent is transmitted across generations (persistence of innate ability vs. the impact of parental education) and permit different forms of labor to be imperfect substitutes, thereby generating general equilibrium feedback effects from policies to relative wages of skilled and unskilled workers.

We show that subsidizing higher education has important redistributive benefits, by shrinking the college wage premium in general equilibrium. This Stiglitz (1982) effect of fiscal policy on relative factor prices may make progressive taxes and education subsidies potential policy substitutes for providing social insurance. ${ }^{1}$ We also argue that a full characterization of the transition path is crucial for policy evaluation. In our quantitative analysis we find that optimal education policies are always characterized by generous tuition subsidies. The optimal degree of income tax progressivity however crucially depends on whether transitional costs of policies are explicitly taken into account and how strongly the college wage premium responds to policy changes in general equilibrium.

Our benchmark economy models skilled and unskilled labor as imperfect substitutes in the production of final output, following the empirical literature since Katz and Murphy (1992) or Borjas (2003), with a substitution elasticity of 1.4. When maximizing utilitarian social welfare valuing transitional generations in this economy, we document in section 6.2.1 that the optimal policy is characterized by a massive education

1 Heathcote, Storesletten and Violante (2014) also evaluate the quantitative importance of general equilibrium effects of fiscal policy on relative factor prices in their analysis of an analytically tractable dynamic incomplete markets economy. Similarly, Rothschild and Scheuer (2013) stress the Stiglitz effect in their study of optimal redistributive fiscal policy in a Roy model where households self-select into different sectors, rather than different skill (education) levels, as in this work. 
subsidy of $\theta=150 \%$ of the college tuition $\operatorname{cost}^{2}$ and a tax system that is characterized by only moderate tax progressivity. We model a simple parametric tax system with a tax deduction of $d$ times average income (such that $d$ is one measure of tax progressivity) and a constant marginal tax rate of $\tau_{l}$ for incomes exceeding this threshold. The optimal tax deduction $d$ amounts to only about $d=6 \%$ of average income and the constant marginal tax rate stands at approximately $\tau_{l}=22 \%$. This intertemporally optimal tax reform generates welfare gains equivalent to more than $3 \%$ of permanent consumption, relative to the status quo policy, which is calibrated to broadly approximate current U.S. policy $\left(\theta=39 \%, \tau_{l}=28 \%, d=27 \%\right)$.

In order to explain the intuition behind this result it is instructive to proceed in three steps. Consider first an economy in which fiscal policy has no effect on the college wage premium (because skilled and unskilled labor are perfect substitutes) and transitional dynamics are ignored. ${ }^{3}$ In the appendix to this paper we construct and analyze a simple version of this model ${ }^{4}$ with fixed (but education-specific) labor productivity and show analytically that the lack of explicit private insurance against idiosyncratic wage and thus income risk justifies the provision of public insurance via progressive taxation, even though such a policy discourages college attendance. We also demonstrate how education subsidies can partially offset this distortion and thus complement the progressive tax policy. When we turn this simple model into a full quantitative life cycle equilibrium economy to analyze optimal steady state policy quantitatively in section 6.2.2, we indeed find that both policies complement each other in the steady state, in that both the public eduction subsidy $\theta$ and the relative tax deduction $d$ increase from their status quo levels of $(\theta=38.8 \%, d=27.1 \%)$ to $(\theta=170 \%, d=31 \%)$. That is, ignoring general equilibrium relative wage effects and transitional dynamics, the optimal tax system is more progressive than the status quo U.S. system.

In addition to improved social insurance, the substantial welfare gain (in the order of $2.6 \%$ of lifetime consumption) stem from the fact that per capita output (and thus consumption) increases in the long run despite average hours worked falling. This is feasible since an education boom (the share of college educated individuals increases by $50 \%$ in the long run) improves the skill distribution in the economy. However, building up the skill distribution takes time (as new college students constitute only a small part of the overall workforce), and thus in a second step towards explaining our benchmark results from section 6.2.1, we conduct an optimal policy transition analysis. In section 6.2.3 we show that implementing the steady state optimal policy along the transition drives the economy into a severe recession induced by the decline in labor

2 This implies that, effectively, the government not only provides free tertiary education, but also covers part of the living expenses of those going to college.

3 We first analyzed this case in our previous work, Krueger and Ludwig (2013).

4 This version of the model in turn builds on the work by Bovenberg and Jacobs (2005), but is tailored to mimic our quantitative life cycle model as closely as possible to provide intuition for our quantitative results. 
supply and capital accumulation on account of the higher marginal tax rates required to pay for the more generous education subsidy and higher tax deduction. Therefore taking the transitional costs into account the steady state optimal policy actually entails significant welfare losses relative to the status quo, in the order of $2.8 \%$ of lifetime consumption. In contrast, the optimal policy reform, taking the transition path explicitly into account, still calls for substantially higher education subsidies than the current status quo, but now calls for less progressive taxes (both relative to the steady state optimum of $d=30 \%$ as well as the status quo of $d=27.1 \%$ ) in order to avoid the short-run recession induced by higher marginal tax rates. The optimal tax deduction falls to $d=10 \%$ of average income and optimal marginal taxes decrease from a status quo of $27.5 \%$ to $23 \%$. The finding that an explicit consideration of transitional dynamics in the analysis of education finance reform in models with endogenous human capital accumulation is potentially very important for optimal tax design is the first main quantitative conclusion of this paper.

Relative to the benchmark economy, the economies considered in steps 1 and 2 of the analysis abstract from changes in the college wage premium induced by the policy reform and the economic transition it triggers. When we relax this assumption and characterize optimal policy under our preferred benchmark substitution elasticity between skilled and unskilled labor of 1.4 (that is, return to the results from section 6.2.1) our main optimal policy conclusions from step 2 (large education subsidy, modest tax progressivity when the transition path is taken into account, substantial welfare gains in the order of $3 \%$ of lifetime consumption) remain intact: the optimal education subsidy rate is $150 \%$, the optimal tax deduction now only $6 \%$ of average income and marginal taxes are at $22 \%$. However, there are important qualifications. First, with imperfect substitutes the strong rationale for progressive taxes disappears even in the steady state (the optimal steady state policy has a subsidy rate of $200 \%$ and a tax deduction of $10 \%$ of mean income). Since the generous education subsidy induces more individuals to go to college, the college wage premium falls in equilibrium which constitutes a policy substitute for redistributive tax progressivity. ${ }^{5,6}$ That general equilibrium wage effects can turn education subsidies and progressive taxes from policy complements to policy substitutes is the second main quantitative conclusion of this work.

The paper is organized as follows. After relating our contribution to the literature in the next section, in section 3 we set up our quantitative life cycle model and define equilibrium for a given fiscal policy of the government. Section 4 describes the optimal tax problem of the government, including its objective and the instruments available to the government. After calibrating the economy to U.S. data (including current tax

5 The policy-induced reduction in the college wage premium in turn weakens education incentives; thus a larger increase in subsidies is required to achieve a given expansion in educational attainments and the long-run effect of the policy on educational attainment is smaller.

6 Given that the optimal tax policy is already not very progressive in the steady state, the policy differences between the steady state and the transition are qualitatively similar to the perfect substitutes case, but quantitatively not very important. 
and education policies) in section 5 of the paper, section 6 displays the results and provides the interpretation of the optimal taxation analysis. Section 7 concludes. The appendix makes explicit the analysis of the simple model. It also contains details of the calibration and the computation of the model.

\section{Relation to the Literature}

Our paper aims at characterizing the optimal progressivity of the income tax code in a life cycle economy in which the public provision of redistribution and income insurance through taxation and education policies is desirable, but where progressive taxes not only distort consumption-savings and labor-leisure choices, but also household human capital accumulation choices. It is most closely related to the studies by Conesa and Krueger (2006), Conesa et al. (2009) and Karabarbounis (2012). Relative to their steady state analyses we provide a full quantitative transition analysis of the optimal tax code in a model with endogenous education choices. ${ }^{7}$ In stressing the importance of the sources of the intergenerational transmission of talent (for college) and the general equilibrium wage effects of education policies for optimal policies our paper builds especially strongly on the study by Abbott, Gallipoli, Meghir and Violante (2013) whose pioneering work models financial aid and college loan programs much more explicitly than our paper but does not study the optimal fiscal policy and education policy mix.

In our earlier paper, Krueger and Ludwig (2013) we characterized the optimal policy transition in a model with college choice in which the innate ability distribution of children for college was exclusively determined by the education level of the parents, and in which policies have no general equilibrium impact on the relative wages of college versus non-college labor. Consequently education subsidies are a potent tool to encourage college attendance but have no redistributive benefits through reducing the college wage premium. Both features stacked the deck for finding large education subsidies and policy complementarity between these policies and redistributive taxation. Relative to this work here we use micro data to discipline the relative importance of parental education and parental innate ability in the intergenerational transmission of skills, ${ }^{8}$ and we model general equilibrium wage effects explicitly. We show that whereas the large education subsidies remain optimal, the optimal degree of tax progressivity declines substantially. Policy complements turn into policy substitutes.

Our paper follows a long tradition in the literature that uses quantitative overlapping generations models in the spirit of Hubbard and Judd (1986) and Auerbach and Kotlikoff (1987), but enriched by uninsurable idiosyncratic earnings risk as in Bewley

7 Bakis et al. (2014), Fehr and Kindermann (2015) and Kindermann and Krueger (2015) also compute optimal tax transitions, but abstract from endogenous human capital accumulation.

8 Our model-implied impact of education subsidy payments on college attendance is consistent with Dynarski's (2003) empirical findings. 
(1986), Huggett $(1993,1997)$ and Aiyagari (1994), to study the optimal structure of the tax code in the Ramsey tradition, see Chamley (1986) and Judd (1985). The optimal tax code in life cycle economies with a representative household in each generation was characterized in important papers by Alvarez et al. (1992), Erosa and Gervais (2002), Garriga (2003), Gervais (2012), Bovenberg and Jacobs (2005), Jacobs and Bovenberg (2010), and in economies with private information in the Mirrleesian (Mirrlees 1971) tradition, by Judd and Su (2006), Fukujima (2010), Bohacek and Kapicka (2008), Kapicka (2012), Findeisen and Sachs $(2013,2014)^{9}$ and Weinzierl (2011). ${ }^{10}$

The study of optimal redistributive tax and education policies in heterogeneous agent models with endogenous human capital was pioneered by Benabou (2002). This paper as well as Bovenberg and Jacobs (2005) point out that education subsidies might be effective in mitigating the distortions of education decisions from a progressive income tax code, making both complementary policy tools. As in their theoretical analyses that abstract from explicit life cycle modeling and savings choices we therefore study such subsidies explicitly as part of the optimal policy mix in our quantitative investigation. Our focus of the impact of the tax code and education subsidies on human capital accumulation decisions also strongly connects our work to the studies by Heckman et al. (1998, 1999), Caucutt et al. (2006), Bohacek and Kapicka (2012), Kindermann (2012), Abbott et al. (2013), Holter (2014), Winter (2014) and Guvenen et al. (2014), although the characterization of the optimal tax code is not the main objective of these papers.

In our attempt to contribute to the literature on (optimal) taxation in life cycle economies with idiosyncratic risk and human capital accumulation we explicitly model household education decisions (and government subsidies thereof) in the presence of borrowing constraints and the intergenerational transmission of human capital as well as wealth. Consequently our works builds upon the massive theoretical and empirical literature investigating these issues, studied and surveyed in, e.g. Keane and Wolpin (2001), Cunha et al. (2006), Holmlund et al. (2011), Lochner and Monge (2011). ${ }^{11}$

9 The focus of the last four papers on optimal income taxation in the presence of human capital accumulation make them especially relevant for our work, although they abstract from explicit life cycle considerations.

10 There is also a large literature on the positive effects of various taxes on allocations and prices in life cycle economies, see, e.g., Hubbard and Judd (1986) and Castañeda et al. (1999). The redistributive and insurance role of progressive taxation in models with heterogeneous households is also analyzed in Domeij and Heathcote (2004) and Heathcote, Storesletten and Violante (2014).

11 A comprehensive survey of this literature is well beyond the scope of this paper. We will reference the papers on which our modeling assumptions or calibration choices are based specifically in sections 3 and 5 . 


\section{The Quantitative Model}

In this section we lay out the quantitative life cycle model that we will employ in our optimal policy analysis.

\subsection{Demographics}

Population grows at the exogenous rate $\chi$. We assume that parents give birth to children at the age of $j_{f}$ and denote the fertility rate of households by $f$, assumed to be the same across education groups. ${ }^{12}$ Notice that $f$ is also the number of children per household. Further, let $\varphi_{j}$ be the age-specific survival rate. We assume that $\varphi_{j}=1$ for all $j=0, \ldots, j_{r}-1$ and $0<\varphi_{j} \leq 1$ for all $j=j_{r}, \ldots, J-1$, where $j_{r}$ is the fixed retirement age ( $j_{r}-1$ is the last working age before retirement) and $J$ denotes the maximum age (hence $\varphi_{J}=0$ ). The population dynamics are then given by

$$
\begin{aligned}
N_{t+1,0} & =f \cdot N_{t, j} \\
N_{t+1, j+1} & =\varphi_{j} \cdot N_{t, j}, \quad \text { for } j=0, \ldots, J .
\end{aligned}
$$

Observe that the population growth rate is given by

$$
\chi=f^{\frac{1}{j_{f}^{+1}}}-1 \text {. }
$$

\subsection{Technology}

We refer to workers that have completed college as skilled, the others as unskilled. Thus the skill level $s$ of a worker falls into the set $s \in\{n, c\}$ where $s=c$ denotes college educated individuals. We assume that skilled and unskilled labor are imperfectly substitutable in production but that within skill groups labor is perfectly substitutable across different ages. Let $L_{t, s}$ denote aggregate labor of skill $s$, measured in efficiency units and let $K_{t}$ denote the capital stock.

Total labor efficiency units at time $t$, aggregated across both education groups, is then given by

$$
L_{t}=\left(L_{t, n}^{\rho}+L_{t, c}^{\rho}\right)^{\frac{1}{\rho}}
$$

where $\frac{1}{1-\rho}$ is the elasticity of substitution between skilled and unskilled labor. ${ }^{13}$ As long as $\rho<1$, skilled and unskilled labor are imperfect substitutes in production,

12 Note that due to the endogeneity of the education decision in the model, if we were to allow differences in the age at which households with different education groups have children, it is hard to assure that the model has a stationary joint distribution over age and skills.

13 Katz and Murphy (1992) report an elasticity of substitution across education groups of $\sigma=1.4$. This is also what Borjas (2003) finds, using a different methodology and dataset. 
and the college wage premium will endogenously respond to changes in government policy.

Aggregate labor is combined with capital to produce output $Y_{t}$ according to a standard Cobb-Douglas production function

$$
Y_{t}=F\left(K_{t}, L_{t}\right)=K_{t}^{\alpha} L_{t}^{1-\alpha}=K_{t}^{\alpha}\left[\left(L_{t, n}^{\rho}+L_{t, c}^{\rho}\right)^{\frac{1}{\rho}}\right]^{1-\alpha}
$$

where $\alpha$ measures the elasticity of output with respect to the input of capital services.

Perfect competition among firms and constant returns to scale in the production function implies zero profits for all firms and an indeterminate size distribution of firms. Thus there is no need to specify the ownership structure of firms in the household sector, and without loss of generality we can assume the existence of a single representative firm.

This representative firm rents capital and hires the two skill types of labor on competitive spot markets at prices $r_{t}+\delta$ and $w_{t, s}$, where $r_{t}$ is the interest rate, $\delta$ the depreciation rate of capital and $w_{t, s}$ is the wage rate per unit of labor of skill $s$. Furthermore, denote by $k_{t}=\frac{K_{t}}{L_{t}}$ the "capital intensity" - defined as the ratio of capital to the CES aggregate of labor. Profit maximization of firms implies the standard conditions

$$
\begin{aligned}
r_{t} & =\alpha k_{t}^{\alpha-1}-\delta \\
w_{t, n} & =(1-\alpha) k_{t}^{\alpha}\left(\frac{L_{t}}{L_{t, n}}\right)^{1-\rho}=\omega_{t}\left(\frac{L_{t}}{L_{t, n}}\right)^{1-\rho} \\
w_{t, c} & =(1-\alpha) k_{t}^{\alpha}\left(\frac{L_{t}}{L_{t, c}}\right)^{1-\rho}=\omega_{t}\left(\frac{L_{t}}{L_{t, c}}\right)^{1-\rho},
\end{aligned}
$$

where $\omega_{t}=(1-\alpha) k_{t}^{\alpha}$ is the marginal product of total aggregate labor $L_{t}$. The college wage premium follows as

$$
\frac{w_{t, c}}{w_{t, n}}=\left(\frac{L_{t, n}}{L_{t, c}}\right)^{1-\rho}
$$

and depends on the relative supplies of non-college to college labor (unless $\rho=1$ ) and the elasticity of substitution between the two types of skills.

\subsection{Household Preferences and Endowments}

\subsubsection{Preferences}

Households are born at age $j=0$ and form independent households at age $j_{a}$, standing in for age 18 in real time. Households give birth at the age $j_{f}$ and children live with adult households until they form their own households. Hence for ages $j=j_{f}, \ldots, j_{f}+$ $j_{a}-1$ children are present in the parental household. Parents derive utility from per 
capita consumption of all household members and leisure that are representable by a standard time-separable expected lifetime utility function

$$
E_{j_{a}} \sum_{j=j_{a}}^{J} \beta^{j-j_{a}} u\left(\frac{c_{j}}{1+\mathbf{1}_{\mathcal{J}_{s}} \zeta f}, \ell_{j}\right)
$$

where $c_{j}$ is total consumption, $\ell_{j}$ is leisure and $\mathbf{1}_{\mathcal{J}_{s}}$ is an indicator function taking the value one during the period when children are living in the respective household, that is, for $j \in \mathcal{J}_{s}=\left[j_{f}, j_{f}+j_{a}-1\right]$, and zero otherwise. $0 \leq \zeta \leq 1$ is an adult equivalence parameter. Expectations in the above are taken with respect to the stochastic processes governing mortality and labor productivity risk as well as with respect to survival risk.

We model an additional form of altruism of households towards their children. At parental age $j_{f}$, when children leave the house, the children's expected lifetime utility enters the parental lifetime utility function with a weight $v \beta^{j_{f}}$, where the parameter $v$ measures the strength of parental altruism. ${ }^{14}$

\subsubsection{Initial Endowments and Human Capital Accumulation Technology}

At age $j=j_{a}$, before any decision is made, households draw their innate ability to go to college, $e \in\left\{e_{1}, e_{2}, \ldots, e_{N}\right\}$ according to a distribution $\pi(e \mid$.$) that may depend$ on the characteristics of their parents, including parental education $s_{p}$ and parental labor productivity to be described below. ${ }^{15}$ Innate ability also affects future wages directly and independent of education, in a stochastic way, described below. A young household with ability $e$ incurs a per-period resource cost of going to college $w_{t, c} \kappa$ that is proportional to the aggregate wage of the high-skilled, $w_{t, c} \cdot{ }^{16}$ In case the government chooses to implement education subsidies, a fraction $\theta_{t}$ of the resource cost is borne by the government. In addition, a constant fraction $\theta_{p r}$ of the education costs is borne by private subsidies, paid from accidental bequests described below. We think of $\theta_{p r}$ as a policy invariant parameter to be calibrated, and introduce it to capture the fact that, empirically, a significant share of university funding comes from alumni donations and support by private foundations.

Going to college also requires a fraction $\xi(e) \in[0,1]$ of time at age $j_{a}$, in the period

14 Evidently the exact timing when children lifetime utility enters that of their parents is inconsequential.

15 Ability $e$ in our model does capture innate ability as well as all learned characteristics of the individual at the age of the college decision. In our model one of the benefits of going to college is to be able to raise children that will (probabilistically) be more able to go to college.

16 In addition to a monetary cost Abbott et al. (2013) model a "psychic stress" formulation of costs based on Heckman, Lochner and Todd (2006). Our specification is closer to Caucutt et al. (2006) where the costs stand in for hiring a teacher to acquire education. 
in which the household attends school. ${ }^{17}$ The dependence of the time cost function $\xi$ on innate ability to go to college reflects the assumption that more able people require less time to learn and thus can enjoy more leisure time or work longer hours while attending college (the alternative uses of an individual's time). ${ }^{18}$ A household that completed college has skill $s=c$, a household that did not has skill $s=n$.

Households start their economic life at age $j_{a}$ with an initial endowment of financial wealth $b \geq 0$ received as inter-vivo transfer from their parents. ${ }^{19}$ Parents make these transfers, assumed to be noncontingent on the child's education decision ${ }^{20}$, at their age $j_{f}$, after having observed their child's ability draw $e$. This transfer is restricted to be nonnegative. In addition to this one-time intentional intergenerational transfer $b$, all households receive transfers from accidental bequests. We assume that assets of households that die at age $j$ are redistributed uniformly across all households of age $j-j_{f}$, that is, among the age cohort of their children. Let these age dependent transfers be denoted by $\operatorname{Tr}_{t, j}$

\subsubsection{Labor Productivity}

In each period of their lives households are endowed with one unit of productive time. A household of age $j$ with skill $s \in\{n, c\}$ earns a wage

$$
w_{t, s} \epsilon_{j, s} \gamma \eta
$$

per unit of time worked. Wages depend on a deterministic age profile $\epsilon_{j, s}$ that differs across education groups, on the skill-specific average wage $w_{t, s}$, a fixed effect $\gamma \in \Gamma_{s}=\left\{\gamma_{l, s}, \gamma_{h, s}\right\}$ that spreads out wages within each education group and remains constant over the life cycle, and an idiosyncratic stochastic shock $\eta$. The probability of drawing the high fixed effect prior to labor market entry is a function of the ability of the household, and denoted by $\pi_{s}(\gamma \mid e)$. The stochastic shock $\eta$ is mean-reverting and follows an education-specific Markov chain with states $\mathcal{E}_{s}=\left\{\eta_{s 1}, \ldots, \eta_{s M}\right\}$ and transitions $\pi_{s}\left(\eta^{\prime} \mid \eta\right)>0$. Let $\Pi_{s}$ denote the invariant distribution associated with $\pi_{s}$. Prior to making the education decision a household's idiosyncratic shock $\eta$ is drawn from $\Pi_{n}$. We defer a detailed description of the exact forms for $\pi_{s}(\gamma \mid e)$ and $\pi_{s}\left(\eta^{\prime} \mid \eta\right)$

17 In the quantitative implementation of the model a period will last four years, and thus households attend college for one model period.

18 With this time cost we also capture utility losses of poorer households who have to work part-time to finance their college education.

19 This is similar to Abbott et al. (2013). We model this as a one time payment only. The transfer payment captures the idea that parents finance part of the higher education of their children. Our simplifying assumptions of modeling these transfers are a compromise between incorporating directed inter-generational transfers of monetary wealth in the model and computational feasibility.

20 Note that parents of course understand whether, given $b$, children will go to college or not, and thus can affect this choice by giving a particular $b$. 
to the calibration section. ${ }^{21}$ Thus at the beginning of every period in working life the individual state variables of the household include $(j, \gamma, s, \eta, a)$, the household's age $j$, fixed effect $\gamma$, education $s$, stochastic labor productivity shock $\eta$ and assets $a$.

\subsection{Market Structure}

We assume that financial markets are incomplete in that there is no insurance available against idiosyncratic mortality and labor productivity shocks. Households can selfinsure against this risk by accumulating a risk-free one-period bond that pays a real interest rate of $r_{t}$. In equilibrium the total net supply of this bond equals the capital stock $K_{t}$ in the economy, plus the stock of outstanding government debt $B_{t}$.

Furthermore, we severely restrict the use of credit to self-insure against idiosyncratic labor productivity and thus income shocks by imposing a strict credit limit. The only borrowing we permit is to finance a college education. Households that borrow to pay for college tuition and consumption while in college face age-dependent borrowing limits of $\underline{A}_{j, t}$ (whose size depends on the degree to which the government subsidizes education) and also face the constraint that their balance of outstanding student loans cannot increase after college completion. This assumption rules out that student loans are used for general consumption smoothing.

The constraints $\underline{A}_{j, t}$ are set such that student loans need to be fully repaid by age $j_{r}$ at which early mortality sets in. This insures that households can never die in debt and we do not need to consider the possibility and consequences of personal bankruptcy. Beyond student loans we rule out borrowing altogether. This, among other things, implies that households without a college degree can never borrow. As the calibration of the model will make clear, we think of the constraints $\underline{A}_{j, t}$ being determined by public student loan programs, and thus one may interpret the borrowing limits as government policy parameters that are being held fixed in our analysis.

21 The purpose of introducing the fixed effect $\gamma$ instead of making wages directly depend on ability $e$ is mainly computational (although we think it is plausible to make ability to succeed in college and ability in the labor market imperfectly correlated).

In order to permit the share of households that go to college to vary smoothly with economic policy it is important that the set $\left\{e_{1}, e_{2}, \ldots, e_{N}\right\}$ is sufficiently large. However, given the large state space for households of working age keeping track of the state variable $e$ is costly; stochastically mapping $e$ into the fixed effect $\gamma$ after the education decision and restricting $\gamma$ to take only two possible values (for each education group) reduces this burden significantly. 


\subsection{Government Policies}

The government needs to finance an exogenous stream $G_{t}$ of non-education expenditures and an endogenous stream $E_{t}$ of education expenditures. It can do so by issuing government debt $B_{t}$, by levying linear consumption taxes $\tau_{c, t}$ and income taxes $T_{t}\left(y_{t}\right)$ which are not restricted to be linear. The initial stock of government debt $B_{0}$ is given. We restrict attention to a tax system that discriminates between the sources of income (capital versus labor income), taxes capital income $r_{t} a_{t}$ at the constant rate $\tau_{k, t}$, but permits labor income taxes to be progressive or regressive. We take consumption and capital income tax rates $\tau_{c, t}, \tau_{k, t}$ as exogenously given, but optimize over labor income tax schedules within a simple parametric class.

Specifically, the total amount of labor income taxes paid takes the following simple linear form

$$
\begin{aligned}
T_{t}\left(y_{t}\right) & =\max \left\{0, \tau_{l, t}\left(y_{t}-d_{t} \frac{Y_{t}}{N_{t}}\right)\right\} \\
& =\max \left\{0, \tau_{l, t}\left(y_{t}-Z_{t}\right)\right\}
\end{aligned}
$$

where $y_{t}$ is household taxable labor income, $\frac{Y_{t}}{N_{t}}$ is per capita income in the economy and $Z_{t}=d_{t} \frac{Y_{t}}{N_{t}}$ measures the size of the labor income tax deduction. Therefore for every period there are two policy parameters on the tax side, $\left(\tau_{l, t}, d_{t}\right)$. Note that the tax system is potentially progressive (if $d_{t}>0$ ) or regressive (if $d_{t}<0$ ).

The government uses tax revenues to finance education subsidies $\theta_{t}$ and exogenous government spending

$$
G_{t}=g y \cdot Y_{t}
$$

where the share of output $g y=\frac{G_{t}}{Y_{t}}$ commanded by the government is a parameter to be calibrated from the data. ${ }^{22}$

In addition, the government administers a pure pay-as-you-go social security system that collects payroll taxes $\tau_{s s, t}$ and pays benefits $p_{t, j}(\gamma, s)$, which depend on the wages a household has earned during her working years, and thus on her characteristics $(\gamma, s)$ as well as on the time period in which the household retired (which, given today's date $t$ can be inferred from the current age $j$ of the household). In the calibration section we describe how we approximate the current U.S. system with its progressive benefit schedule through the function $p_{t, j}(\gamma, s)$. Since we are interested in the optimal progressivity of the income tax schedule given the current social security system it is important to get the progressivity of the latter right, in order to not bias our conclusion about the desired progressivity of income taxes. In addition, the introduction of social

22 Once we turn to the determination of optimal tax and subsidy policies we will treat $G$ rather than $g y$ as constant. A change in policy changes output $Y_{t}$ and by holding $G$ fixed we assume that the government does not respond to the change in tax revenues by adjusting government spending (if we held $g y$ constant it would). 
security is helpful to obtain more realistic life cycle saving profiles and an empirically more plausible wealth distribution.

Since the part of labor income that is paid by the employer as social security contribution is not subject to income taxes, taxable labor income equals $\left(1-0.5 \tau_{s s, t}\right)$ per dollar of labor income earned, that is

$$
y_{t}=\left(1-0.5 \tau_{s s, t}\right) w_{t, s} \epsilon_{j, s} \gamma \eta l
$$

\subsection{Competitive Equilibrium}

We deal with time sequentially, both in our specification of the model as well as in its computation. For a given time path of prices and policies it is easiest to formulate the household problem recursively, however. In order to do so for the different stages of life we first collect the key decisions and state variables in a time line.

\subsubsection{Time Line}

1. Newborn individuals are economically inactive but affect parental utility until they form a new household at age $j_{a}$.

2. Initial state variables when a new household forms are age $j=j_{a}$, parental education $s_{p}$, parental productivity $\gamma_{p}$, and own education $s=n$ (the household does not have a college degree before having gone to college). Then an ability level $e \sim \pi\left(e \mid s_{p}, \gamma_{p}\right)$ is drawn. Then parents decide on the inter-vivos transfer $b$, which are transfered within the period and thus immediately constitute the initial endowment of assets $a$ for other ages. Then initial idiosyncratic labor productivity $\eta$ is drawn according to $\Pi_{n}$. Thus the state of a household prior to the college decision is $z=\left(j_{a}, e, s=n, \eta, a=b /\left(1+r\left(1-\tau_{k}\right)\right)\right) .{ }^{23}$

3. Given state $z$, at age $j_{a}$ the educational decision is made. If a household decides to go to college, she immediately does so at age $j_{a}$, and her education state switches to $s=c$ at that age. Then households draw their labor productivity fixed effect $\gamma$ from the education- and ability-contingent distribution $\pi(\gamma \mid s, e)$.

4. At age $j_{a}$, but after the education decision has been made, the household problem differs between non-college and college households since the latter need to spend time and resources on college. A household that goes to college but works part time does so for non-college wages:

$$
w_{t, n} \epsilon_{j, n} \gamma \eta
$$

23 For all ages $j>j_{a}$ assets $a$ brought into the period generate gross revenue $\left(1+r\left(1-\tau_{k}\right)\right) a$. Given our timing assumption inter-vivo transfers $b$ generate gross revenue of $b$. Thus the initial asset state of households of age $j_{a}$ is $a=b /\left(1+r\left(1-\tau_{k}\right)\right)$. 
where $\eta$ is drawn as described above. Observe that $\gamma$ is fixed whereas $\eta$ is drawn from the non-college distribution. At the end of the college period $j_{a}$ the idiosyncratic shock $\eta$ of college-bound households is re-drawn from the college distribution $\Pi_{c}$ and now evolves according to $\pi_{c}\left(\eta^{\prime} \mid \eta\right)$ for those with $s=c$. Furthermore college-educated households draw their fixed effect from the distribution $\pi(\gamma \mid c, e)$ prior to entering the labor market.

5. Ages $j_{a}+1, \ldots, j_{f}-1$ : Between age of $j_{f}-1$ and $j_{f}$ the decision problem changes because children now enter the utility function and households maximize over per capita consumption $c_{j} /(1+\zeta f)$.

6. Ages $j_{a}+j_{f}, \ldots, j_{a}+j_{f}-1$ : Between age of $j_{a}+j_{f}-1$ and $j_{a}+j_{f}$ the decision problem changes again since at age $j_{a}+j_{f}$ children leave the household and the decision about the inter-vivos transfer $b$ is made and lifetime utilities of children enter the continuation utility of parents.

7. Age $j_{f}$ : Households make transfers $b$ to their children conditional on observing the skills $e$ of their children.

8. Age $j_{a}+j_{f}+1, \ldots, j_{r}-1$ : Only utility from own consumption and leisure enters the lifetime utility at these ages.

9. Ages $j=j_{r}, \ldots, J$ : Households are now in retirement and only earn income from capital and from social security benefits $p_{t, j}(e, s)$.

The key features of this time line are summarized in figure 1.

\subsubsection{Recursive Problems of Households}

We now spell out the dynamic household problems at the different stages in the life cycle recursively.

Child at $j=0, \ldots, j_{a}-1$ Children live with their parents and command resources, but do not make own economic decisions.

Education decision at $j_{a}$ Before households make the education decision households draw ability $e$, their initial labor productivity $\eta$ and receive inter-vivos transfers $b$. We specify an indicator function for the education decision as $\mathbf{1}_{s}=\mathbf{1}_{s}(e, \eta, b)$, where a value of 1 indicates that the household goes to college. Recall that households, as initial condition, are not educated in the first period, $s=n$ and that age is $j=j_{a}$. The 
education decision solves

$$
\mathbf{1}_{s, t}(e, \eta, b)=\left\{\begin{array}{cc}
1 \quad & \text { if } V_{t}\left(j=j_{a}, e, s=c, \eta, b /\left(1+r\left(1-\tau_{k}\right)\right)\right)> \\
& V_{t}\left(j=j_{a}, e, s=n, \eta, b /\left(1+r\left(1-\tau_{k}\right)\right)\right) \\
0 & \text { otherwise, }
\end{array}\right.
$$

where $V_{t}\left(j_{a}, e, s, \eta, b /\left(1+r\left(1-\tau_{k}\right)\right)\right)$ is the lifetime utility at age $j=j_{a}$, conditional on having chosen (but not completed) education $s \in\{n, c\}$. It is formally given by

$$
V_{t}\left(j_{a}, e, s, \eta, b /\left(1+r\left(1-\tau_{k}\right)\right)\right)=\sum_{\gamma \in \Gamma_{s}} \pi(\gamma \mid s, e) V_{t}\left(j_{a}, e, \gamma, s, \eta, b /\left(1+r\left(1-\tau_{k}\right)\right)\right)
$$

where $V_{t}\left(j_{a}, e, \gamma, s, \eta, b /\left(1+r\left(1-\tau_{k}\right)\right)\right)$ is defined below and is the value function at age $j_{a}$ after the fixed effect has been drawn from $\pi_{s}(\gamma \mid e)$.

Problem at $j=j_{a} \quad$ After having made the education decision at age $j_{a}$ and having drawn the fixed effect $\gamma$ households choose how much to work, how much to consume and how much to save. The dynamic programming problem of college-bound and non-college bound households differ. Households first draw the fixed effect $\gamma$ from distribution $\pi(\gamma \mid s, e)$ and then solve

$$
V_{t}(j, e, \gamma, s, \eta, a)=\max _{\substack{c, l \in\left[0,1-\mathbf{1}_{s} \xi(e)\right] \\ a^{\prime} \geq-\mathbf{1}_{s} \underline{A_{j, t}}}}\left\{u\left(c, 1-\mathbf{1}_{s} \xi(e)-l\right)+\beta \varphi_{j} \sum_{\eta^{\prime}} \pi_{s}\left(\eta^{\prime} \mid \eta\right) V_{t+1}\left(j+1, \gamma, s, \eta^{\prime}, a^{\prime}\right)\right\}
$$

subject to the budget constraint

$$
\begin{aligned}
& \left(1+\tau_{c, t}\right) c+a^{\prime}+\mathbf{1}_{s}\left(1-\theta_{t}-\theta_{p r}\right) \kappa w_{t, c}+T_{t}\left(y_{t}\right)= \\
& \left(1+\left(1-\tau_{k, t}\right) r_{t}\right)\left(a+T r_{t, j}\right)+\left(1-\tau_{s s, t}\right) w_{t, n} \epsilon_{j, n} \gamma \eta l
\end{aligned}
$$

where $y_{t}=\left(1-0.5 \tau_{s s, t}\right) w_{t, n} \epsilon_{j, n} \gamma \eta l$.

Note that ability $e$ is a redundant state variable for non-college bound households at age $j_{a}$, but not for households going to college, since the time loss for doing so still depends on $e$. It does become a redundant state variable at age $j_{a}+1$ and thus does not appear on the right hand side of the Bellman equation above. ${ }^{24}$

Problem at $j_{a}+1, \ldots, j_{f}-1$ At these ages education is completed, thus no time and resource cost for education is being incurred. The problem reads as

$$
V_{t}(j, \gamma, s, \eta, a)=\max _{\substack{c, l \in[0,1] \\ a^{\prime} \geq-\mathbf{1}_{s} \underline{A}_{j, t}}}\left\{u(c, 1-l)+\beta \varphi_{j} \sum_{\eta^{\prime}} \pi_{s}\left(\eta^{\prime} \mid \eta\right) V_{t+1}\left(j+1, \gamma, s, \eta^{\prime}, a^{\prime}\right)\right\}
$$

24 Furthermore we slightly abused notation in that for college-bound households $\eta^{\prime}$ at age $j_{a}$ is drawn from $\Pi_{\mathcal{c}}\left(\eta^{\prime}\right)$ rather than $\pi_{c}\left(\eta^{\prime} \mid \eta\right)$. 
subject to the budget constraint

$$
\left(1+\tau_{c, t}\right) c+a^{\prime}+T_{t}\left(y_{t}\right)=\left(1+\left(1-\tau_{k, t}\right) r_{t}\right)\left(a+T r_{t, j}\right)+\left(1-\tau_{s s, t}\right) w_{t, s} \epsilon_{j, s} \gamma \eta l
$$

where $y_{t}=\left(1-0.5 \tau_{s s, t}\right) w_{t, s} \epsilon_{j, s} \gamma \eta l$.

Problem at ages $j_{f}, \ldots, j_{f}+j_{a}-1$ At these ages children live with the household and thus resource costs of children are being incurred. The problem reads as

$$
V_{t}(j, \gamma, s, \eta, a)=\max _{\substack{c, l \in[0,1] \\ a^{\prime} \geq-\mathbf{1}_{s} \underline{A}_{j, t}}}\left\{u\left(\frac{c}{1+\zeta f^{\prime}}, 1-l\right)+\beta \varphi_{j} \sum_{\eta^{\prime}} \pi_{s}\left(\eta^{\prime} \mid \eta\right) V_{t+1}\left(j+1, \gamma, s, \eta^{\prime}, a^{\prime}\right)\right\}
$$

subject to the budget constraint

$$
\left(1+\tau_{c, t}\right) c+a^{\prime}+T_{t}\left(y_{t}\right)=\left(1+\left(1-\tau_{k, t}\right) r_{t}\right)\left(a+\operatorname{Tr}_{t, j}\right)+\left(1-\tau_{s s, t}\right) w_{t, s} \epsilon_{j, s} \gamma \eta l
$$

where $y_{t}=\left(1-0.5 \tau_{s s, t}\right) w_{t, s} \epsilon_{j, s} \gamma \eta l$

Problem at $j_{f}+j_{a}$ This is the age of the household where children leave the home, parents give them an inter-vivos transfer $b$ and the children's lifetime utility enters that of their parents. The dynamic problem becomes

$$
\begin{aligned}
& V_{t}(j, \gamma, s, \eta, a)=\max _{\begin{array}{l}
c\left(e^{\prime}\right), l\left(e^{\prime}\right) \in[0,1], b\left(e^{\prime}\right) \geq 0 \\
a^{\prime}\left(e^{\prime}\right) \geq-\mathbf{1}_{s} \underline{A}_{j, t}
\end{array}} \sum_{e^{\prime}} \pi\left(e^{\prime} \mid s, \gamma\right)\left\{u\left(c\left(e^{\prime}\right), 1-l\left(e^{\prime}\right)\right)\right. \\
& \quad+\beta \varphi_{j} \sum_{\eta^{\prime}} \pi_{s}\left(\eta^{\prime} \mid \eta\right) V_{t+1}\left(j+1, \gamma, s, \eta^{\prime}, a^{\prime}\left(e^{\prime}\right)\right) \\
& \left.+v \sum_{\eta^{\prime}} \Pi_{n}\left(\eta^{\prime}\right) \max \left[V_{t}\left(j_{a}, e^{\prime}, n, \eta^{\prime}, \frac{b\left(e^{\prime}\right)}{1+r\left(1-\tau_{k}\right)}\right), V_{t}\left(j_{a}, e^{\prime}, c, \eta^{\prime}, \frac{b\left(e^{\prime}\right)}{1+r\left(1-\tau_{k}\right)}\right)\right]\right\}
\end{aligned}
$$

subject to

$$
\begin{aligned}
\left(1+\tau_{c, t}\right) c\left(e^{\prime}\right)+a^{\prime}\left(e^{\prime}\right)+b\left(e^{\prime}\right) f+ & T_{t}\left(y_{t}\right)= \\
& \left(1+\left(1-\tau_{k, t}\right) r_{t}\right)\left(a+T r_{t, j}\right)+\left(1-\tau_{s s, t}\right) w_{t, s} \epsilon_{j, s} \gamma \eta l\left(e^{\prime}\right)
\end{aligned}
$$

where $y_{t}=\left(1-0.5 \tau_{s, t}\right) w_{t, s} \epsilon_{j, s} \gamma \eta l\left(e^{\prime}\right)$

Since parents can observe the ability of their children $e^{\prime}$ before giving the transfer, the transfer $b$ (and thus all other choices in that period) are contingent on $e^{\prime}$. Also notice that all children in the household are identical. Since parents do not observe the initial labor productivity of their children, parental choices cannot be made contingent on it, 
and expectations over $\eta^{\prime}$ have to be taken in the Bellman equation of parents over the lifetime utility of their children. ${ }^{25}$

Problem at $j_{f}+j_{a}+1, \ldots, j_{r}-1$ Now children have left the household, and the decision problem exactly mimics that in ages $j \in\left\{j_{c}+1, \ldots, j_{f}-1\right\}$. Observe that there is a discontinuity in the value function along the age dimension from age $j_{f}+j_{a}$ to age $j_{f}+j_{a}+1$ because the lifetime utility of the child does no longer enter parental utility after age $j_{f}+j_{a}$.

Problem at $j_{r}, \ldots, J$ Finally, in retirement households have no labor income (and consequently no labor income risk). Thus the maximization problem is given by

$$
V_{t}(j, \gamma, s, a)=\max _{c, a^{\prime} \geq 0}\left\{u(c, 1)+\beta \varphi_{j} V_{t+1}\left(j+1, \gamma, s, a^{\prime}\right)\right\}
$$

subject to the budget constraint

$$
\left(1+\tau_{c, t}\right) c+a^{\prime}=\left(1+\left(1-\tau_{k, t}\right) r_{t}\right)\left(a+\operatorname{Tr}_{t, j}\right)+p_{t, j}(\gamma, s)
$$

\subsection{Definition of Equilibrium}

Let $\Phi_{t, j}(\gamma, s, \eta, a)$ denote the share of agents, at time $t$ of age $j$ with characteristics $(\gamma, s, \eta, a) \cdot{ }^{26}$ For each $t$ and $j$ we have $\int d \Phi_{t, j}=1$.

Definition 1 Given an initial capital stock $K_{0}$, initial government debt level $B_{0}$ and initial measures $\left\{\Phi_{0, j}\right\}_{j=0}^{J}$ of households, and given a stream of government spending $\left\{G_{t}\right\}$, a competitive equilibrium is sequences of household value and policy functions $\left\{V_{t}, a_{t}^{\prime}, c_{t}, l_{t}, \mathbf{1}_{s, t}, b_{t}\right\}_{t=0}^{\infty}$, production plans $\left\{Y_{t}, K_{t}, L_{t, n}, L_{t, c}\right\}_{t=0}^{\infty}$, sequences of tax policies, education policies, social security policies and government debt levels $\left\{T_{t}, \tau_{l, t}, \tau_{c, t}, \theta_{t}, \tau_{s s, t}, \tau_{k, t}, p_{t, j}, B_{t}\right\}_{t=0}^{\infty}$, sequences of prices $\left\{w_{t, n}, w_{t, c}, r_{t}\right\}_{t=0}^{\infty}$, sequences of transfers $\left\{\operatorname{Tr}_{t, j}\right\}_{t=0, j}^{\infty}$, and sequences of measures $\left\{\Phi_{t, j}\right\}_{t=1}^{\infty}$ such that

25 Note that we make parents choose transfers noncontingent on the college choice of their children. Mechanically it is no harder to let this choice be contingent on the college choice. Note that permitting such contingency affects choices, since making transfers contingent permits parents to implicitly provide better insurance against $\eta$-risk. If the transfers also could be conditioned on $\eta$, then we conjecture that it does not matter whether they in addition are made contingent on the education decision of the children or not. Note that in any case, parents can fully think through what transfer induces what education decision.

26 For age $j_{a}$ and $s=c$ the state space also includes the ability $e$ of the household, but not the fixed effect $\gamma$. To simplify notation we keep this case distinction implicit whenever there is no room for confusion. 
1. Given prices, transfers and policies, $\left\{V_{t}\right\}$ solve the Bellman equations described in subsection 3.6.2 and $\left\{a_{t}^{\prime}, c_{t}, l_{t}, \mathbf{1}_{s, t}, b_{t}\right\}$ are the associated policy functions.

2. Interest rates and wages satisfy (3a).

3. Transfers are given by

$$
\begin{aligned}
\operatorname{Tr}_{t+1, j-j_{f}+1}=\frac{N_{t, j}}{N_{t+1, j-j_{f}+1}} \int\left(1-\varphi_{j}\right) a_{t}^{\prime}(j, \gamma, s, \eta, a) d \Phi_{t, j}- & \\
& \frac{1}{\sum_{l=j_{f}}^{J} N_{t+1, l-j_{f}+1}} \frac{P E_{t+1}}{1+r_{t+1}\left(1-\tau_{t+1}^{k}\right)}
\end{aligned}
$$

for all $j \geq j_{f}$, where private aggregate education subsidies are given by

$$
P E_{t+1}=\theta_{p r} \kappa w_{t+1, c} N_{t+1, j_{a}} \int_{\{(e, s, \eta, a): s=c\}} d \Phi_{t+1, j_{a}}
$$

4. Government policies satisfy the government budget constraints

$$
\begin{aligned}
\tau_{s s, t} \sum_{s} w_{t, s} L_{t, s} & =\sum_{j=j_{r}}^{J} N_{t, j} \int p_{t, j}(\gamma, s) d \Phi_{t, j} \\
G_{t}+E_{t}+\left(1+r_{t}\right) B_{t} & =B_{t+1}+\sum_{j} N_{t, j} \int T_{t}\left(y_{t}\right) d \Phi_{t, j}+\tau_{k, t} r_{t}\left(K_{t}+B_{t}\right)+\tau_{c, t} C_{t},
\end{aligned}
$$

where, for each household, taxable income $y_{t}$ is defined in the recursive problems in subsection 3.6.2 and aggregate consumption and government education expenditures are given by

$$
\begin{aligned}
E_{t} & =\theta_{t} \kappa w_{t, c} N_{t, j_{a}} \int_{\{(e, \gamma, s, \eta, a): s=c\}} d \Phi_{t, j_{a}} \\
C_{t} & =\sum_{j} N_{t, j} \int c_{t}(j, \gamma, s, \eta, a) d \Phi_{t, j} .
\end{aligned}
$$

5. Markets clear in all periods $t$

$$
\begin{aligned}
L_{t, s} & =\sum_{j} N_{t, j} \int \epsilon_{j, s} \gamma \eta l_{t}(j, \gamma, s, \eta, a) d \Phi_{t, j} \text { for } s \in n, c \\
K_{t+1}+B_{t+1} & =\sum_{j} N_{t, j} \int a_{t}^{\prime}(j, \gamma, s, \eta, a) d \Phi_{t, j} \\
K_{t+1} & =Y_{t}+(1-\delta) K_{t}-C_{t}-C E_{t}-G_{t}-E_{t} .
\end{aligned}
$$

where $Y_{t}$ is given by (2) and it is understood that the integration in (11) is only over individuals with skill s. Also

$$
C E_{t}=\left(1-\theta_{t}\right) \kappa w_{t, c} N_{t, j_{a}} \int_{\{(e, s, \eta, a): s=c\}} d \Phi_{t, j_{a}}
$$

is aggregate private spending on education. 
6. $\Phi_{t+1, j+1}=H_{t, j}\left(\Phi_{t, j}\right)$ where $H_{t, j}$ is the law of motion induced by the exogenous population dynamics, the exogenous Markov processes for labor productivity and the endogenous asset accumulation, education and transfer decisions $a_{t}^{\prime}, \mathbf{1}_{s, t}, b_{t}$.

The law of motion for the measures explicitly states as follows. Define the Markov transition function at time $t$ for age $j$ as

$$
\begin{aligned}
Q_{t, j}((\gamma, s, \eta, a),(\Gamma \times \mathcal{S} \times \mathcal{E} \times \mathcal{A}))= \\
\begin{cases}\sum_{\eta^{\prime} \in \mathcal{E}} \pi_{s}\left(\eta^{\prime} \mid \eta\right) & \text { if } \gamma \in \Gamma, s \in \mathcal{S}, \text { and } a_{t}^{\prime}(j, \gamma, s, \eta, a) \in \mathcal{A} \\
0 & \text { else. }\end{cases}
\end{aligned}
$$

That is, the probability of going from state $(\gamma, s, \eta, a)$ into a set of states $(\Gamma \times \mathcal{S} \times \mathcal{E} \times \mathcal{A})$ tomorrow is zero if that set does not include the current education level and education type, and $\mathcal{A}$ does not include the optimal asset choice. ${ }^{27}$ If it does, then the transition probability is purely governed by the stochastic shock process for $\eta$.

The age-dependent measures are given, for all $j \geq j_{a}$, by

$$
\Phi_{t+1, j+1}((\Gamma \times \mathcal{S} \times \mathcal{E} \times \mathcal{A}))=\int Q_{t, j}(.,(\Gamma \times \mathcal{S} \times \mathcal{E} \times \mathcal{A})) d \Phi_{t, j} .
$$

The initial measure over types at age $j=j_{a}$ (after the college decision has been made) is more complicated. ${ }^{28}$ Households start with assets from transfers from their parents determined by the inter-vivos transfer function $b_{t}$, draw initial mean reverting productivity according to $\Pi_{n}\left(\eta^{\prime}\right)$, determine education according to the index function $\mathbf{1}_{s, t}$ evaluated at their draw $e^{\prime}, \eta^{\prime}$ and the optimal bequests of the parents and draw the fixed effect according to $\pi\left(\gamma^{\prime} \mid s, e^{\prime}\right)$ :

$$
\begin{aligned}
& \Phi_{t+1, j=j_{a}}\left(\left\{e^{\prime}\right\} \times\left\{\gamma^{\prime}\right\} \times\{n\} \times\left\{\eta^{\prime}\right\} \times \mathcal{A}\right) \\
& =\Pi_{n}\left(\eta^{\prime}\right) \sum_{s} \sum_{\gamma} \pi\left(\gamma^{\prime} \mid n, e^{\prime}\right) \pi\left(e^{\prime} \mid s, \gamma\right) \int\left(1-\mathbf{1}_{s, t}\left(e^{\prime}, \eta^{\prime}, b_{t}\left(\gamma, s, \eta, a ; e^{\prime}\right)\right)\right) . \\
& \cdot \mathbf{1}_{\left\{b_{t}\left(\gamma, s, \eta, a ; e^{\prime}\right) /\left(1+r_{t}\left(1-\tau_{k, t}\right)\right) \in \mathcal{A}\right\}} \Phi_{t, j_{f}+j_{a}}(\{\gamma\} \times\{s\} \times d \eta \times d a)
\end{aligned}
$$

27 There is one exception: at age $j=j_{c}$ college-educated households redraw their income shock $\eta$ and draw their fixed effect according to $\pi\left(\gamma^{\prime} \mid c, e\right)$. For this group therefore the transition function at that age reads as

$$
Q_{t, j}((e, c, \eta, a),(\Gamma \times\{c\} \times \mathcal{E} \times \mathcal{A}))=\left\{\begin{array}{cc}
\sum_{\gamma^{\prime} \in \Gamma} \sum_{\eta^{\prime} \in \mathcal{E}} \pi\left(\gamma^{\prime} \mid c, e\right) \Pi_{c}\left(\eta^{\prime}\right) & \text { if } a_{t}^{\prime}(j, e, c, \eta, a) \in \mathcal{A} \\
0 & \text { else. }
\end{array}\right.
$$

28 Part of the complication is that at age $j_{a}$ the individual state space includes ability $e$ which then becomes a redundant state variable. Thus the measures for age $j_{a}$ will be defined over $e$ as well, and it is understood that the transition function $Q_{t, j_{a}}$ from age $j_{a}$ to age $j_{a}+1$ (and only at this age) has as first argument $(e, \gamma, s, \eta, a)$. 


$$
\begin{aligned}
& \Phi_{t+1, j=j_{a}}\left(\left\{e^{\prime}\right\} \times\left\{\gamma^{\prime}\right\} \times\{c\} \times\left\{\eta^{\prime}\right\} \times \mathcal{A}\right) \\
& =\prod_{n}\left(\eta^{\prime}\right) \sum_{s} \sum_{\gamma} \pi\left(\gamma^{\prime} \mid c, e^{\prime}\right) \pi\left(e^{\prime} \mid s, \gamma\right) \int \mathbf{1}_{s, t}\left(e^{\prime}, \eta^{\prime}, b_{t}\left(\gamma, s, \eta, a ; e^{\prime}\right)\right) . \\
& \cdot \mathbf{1}_{\left\{b_{t}\left(\gamma, s, \eta, a ; e^{\prime}\right)\left(1+r_{t}\left(1-\tau_{k, t}\right)\right) \in \mathcal{A}\right\}} \Phi_{t, j_{f}+j_{a}}(\{\gamma\} \times\{s\} \times d \eta \times d a) .
\end{aligned}
$$

Definition 2 A stationary equilibrium is a competitive equilibrium in which all individual functions and all aggregate variables are constant over time.

\section{Thought Experiment}

\subsection{Social Welfare Function}

The social welfare function is Utilitarian for people initially alive

$$
\operatorname{SWF}(\mathcal{T})=\sum_{j} N_{1, j} \int V_{1}(j, \gamma, s, \eta, a ; \mathcal{T}) d \Phi_{1, j},
$$

where $V_{1}(. ; \mathcal{T})$ is the value function in the first period of the transition induced by new tax system $(\mathcal{T})$ and $\Phi_{1}=\Phi_{0}$ is the initial distribution of households in the stationary equilibrium under the status quo policy. ${ }^{29}$

\subsection{Optimal Tax System}

In our optimal policy analysis we hold constant the capital income and consumption tax rate as well as the pension contribution rate (and the borrowing constraints for student loans $\underline{A}_{j, t}$ ) and optimize over labor income taxes and education subsidy rates. Therefore, given initial conditions $\left(K_{0}, B_{0}\right)$, consumption taxes, capital income taxes, a pension system, borrowing constraints and a cross-section of households $\Phi_{0}$ determined by a stationary (to be calibrated policy $\tau_{l, 0}, \theta_{0}, d_{0}, b_{0}=B_{0} / Y_{0}$ ), the optimal tax reform is defined as the sequence $\mathcal{T}^{*}=\left\{\tau_{l, t}, \theta_{t}, d_{t}, B_{t}\right\}_{t=1}^{\infty}$ that maximizes the social welfare function, i.e., that solves

$$
\mathcal{T}^{*} \in \arg \max _{\mathcal{T} \in \Gamma} \operatorname{SWF}(T)
$$

Here $\Gamma$ is the set of policies for which an associated competitive equilibrium exists. Unfortunately the set $\Gamma$ is too large a policy space to optimize over. Our objective here

29 Note that future generations' lifetime utilities are implicitly valued through the value functions of their parents. Of course there is nothing wrong in principle to additionally include future generations' lifetime utility in the social welfare function with some weight, but this adds additional free parameters (the social welfare weights). 
is to characterize the optimal one-time policy reform, by restricting the sequences that are being optimized over to

$$
\begin{aligned}
\tau_{l, t} & =\tau_{l, 1} \\
\theta_{t} & =\theta_{1} \\
d_{t} & =d_{1}
\end{aligned}
$$

for all $t \geq 1$. Note that the associated debt to GDP ratio will of course not be constant over time. Since all admissible policies defined by $\left(\tau_{l, 1}, \theta_{1}, d_{1}\right)$ have to lie in $\Gamma$, from the definition of equilibrium there must be an associated sequence of $\left\{B_{t}\right\}$ such that the government budget constraint is satisfied in every period. This imposes further restrictions on the set of possible triples $\left(\tau_{l, 1}, \theta_{1}, d_{1}\right)$ over which the optimization of the social welfare function is carried out, i.e., the path of government debt has to be consistent with initial conditions and a long-run stationary equilibrium.

\section{Calibration}

\subsection{Demographics}

We take survival probabilities from the Social Security Administration life tables. The total fertility rate $f$ in the economy is assumed to be $f=1.14$, reflecting the fact that a mother on average has about $2 f=2.28$ children. This number also determines the population growth rate, cf. equation (1). Each period in the model has a length of four years. Children are born with age 0 and form households at biological age 18. We discard the first two years of childhood and accordingly set $j_{a}=\frac{18-2}{4}=4$. Households require 4 actual years to complete a college education and therefore exit college at model age $j_{c}=j_{a}+1=5$. They have children at biological age 30, which is model age $j_{f}=7$. Retirement occurs at biological age 66 (age bin 62-65 is the last working period of life), hence $j_{r}=16$. The maximum life span is 101 years, i.e., the last period households are alive is biological age bin 98-101 and accordingly $J=24$.

\subsection{Labor Productivity Process}

Recall that a household of age $j$ with education $s \in\{n, c\}$, fixed effect $\gamma$ and idiosyncratic shock $\eta$ earns a wage of

$$
w_{t, s} \epsilon_{j, s} \gamma
$$

where $w_{s}$ is the skill-specific wage per labor efficiency unit in period $t$.

We estimate the deterministic, age- and education-specific component of labor productivity $\left\{\varepsilon_{j, s}\right\}$ from PSID data (cf. Ludwig, Schelkle and Vogel 2012) and normalize the mean productivity at the age of college completion, $j_{c}=j_{a}+1$, for $s=n$ to $\epsilon_{j_{c}, n}=1$. 
The estimated profile $\epsilon_{j_{c}, c}$ is scaled up by a fixed constant, $\varepsilon$, such that the average college wage premium in the model is $80 \%$, in line with U.S. data for the later part of the 2000's (see, e.g., Heathcote et al. 2010).

We choose the stochastic mean reverting component of wages $\eta$ as a two state Markov chain with education-specific states for log-wages $\left\{-\sigma_{s}, \sigma_{s}\right\}$ and transition matrix

$$
\Pi=\left(\begin{array}{cc}
\pi_{s} & 1-\pi_{s} \\
1-\pi_{s} & \pi_{s}
\end{array}\right) .
$$

In order to parameterize this Markov chain we first estimate the following process on the education-specific PSID samples selected by Karahan and Ozkan (2012):

$$
\begin{aligned}
\log w_{t} & =\alpha+z_{t} \\
z_{t} & =\varrho z_{t-1}+\eta_{t}
\end{aligned}
$$

where $\alpha$ is an individual-specific fixed effect that is assumed to be normally distributed (with cross-sectional variance $\sigma_{\alpha}^{2}$ ). The estimation results are summarized in the left part of table $1 .^{30}$

For each education group we choose the two numbers $\left(\pi_{s}, \sigma_{s}\right)$ such that the two-state Markov chain for wages we use has exactly the same persistence and conditional variance as the $\mathrm{AR}(1)$ process estimated above. ${ }^{31}$ This yields parameter choices given in the right part of table 1.

After de-logging, the wage states are normalized so that the mean of the stochastic component of wages equals 1 . We observe that college educated agents face somewhat smaller wage shocks, but that these shocks are slightly more persistent than for noncollege educated households.

This leaves us with the fixed component of wages $\gamma \in\left\{\gamma_{l, s}, \gamma_{h, s}\right\}$ drawn from an ability-dependent distribution $\pi(\gamma \mid s, e)$. We calibrate the parameters governing this wage component so that our model under the status quo policy matches selected wage or earnings observations from the data. We assume that

$$
\begin{aligned}
& \pi\left(\gamma=\gamma_{h} \mid e, s=c\right)=e \\
& \pi\left(\gamma=\gamma_{h} \mid e, s=n\right)=v \cdot e
\end{aligned}
$$

30 For the details of the sample selection we refer the reader to Karahan and Ozkan (2012) and we thank the authors for providing us with the estimates for the process specified in the main text. In their paper they estimate a richer stochastic process (which, if implemented in our framework, would lead to at least one additional state variable).

31 The (unconditional) persistence of the AR(1) process is given by $\varrho$ and the conditional variance by $\sigma_{\eta}^{2}$ whereas the corresponding statistics for the Markov chain read as $2 \pi_{s}-1$ and $\sigma_{s}^{2}$, respectively.

For a model where a period lasts 4 years and the $\mathrm{AR}(1)$ process is estimated on yearly data, the corresponding statistics are $\varrho^{4}$ and $\left(1+\varrho^{2}+\varrho^{4}+\varrho^{6}\right) \sigma_{\eta}^{2}$. 
and, of course, $\pi\left(\gamma=\gamma_{l} \mid e, s\right)=1-\pi\left(\gamma=\gamma_{h} \mid e, s\right)$. Here $v$ is a parameter. The distribution of $e$ itself is discussed in subsection 5.7. Note that since the $\gamma^{\prime}$ s are education specific and the probability of drawing the (education-specific) high $\gamma_{h, S}$ is a function of ability $e$, the wage benefits of going to college will be ability-specific as well. In appendix 2 we show that this premium is lower for the marginal college attendee (and thus for the households drawn newly into college by an increase in the college subsidy $\theta)$ than the average college wage premium.

The parameters $\left\{\gamma_{l, n}, \gamma_{h, n}, \gamma_{l, c}, \gamma_{h, c}, v\right\}$ are chosen jointly such that the stationary equilibrium of the status quo economy attains the following targets:

- Normalizations: the average $\gamma$ is equal to one for each $s \in\{n, c\}$ [2 targets].

- The estimated variances of the fixed effect for both education groups $\sigma_{\alpha}^{2}$ displayed in the last column of table 1 . Note that the variances in the model are determined, for each $s$, by the spread between $\gamma_{l, s}$ and $\gamma_{h, s}$ (as well as the probabilities of drawing them, see next bullet point) [2 targets]

- The college earnings premium of marginal households (those close to indifferent between attending and not attending under the benchmark policy), as empirically measured by Findeisen and Sachs (2014). In our model this statistic is primarily governed by parameter $v$. [1 target].

\subsection{Technology}

The parameters to be calibrated are $(\alpha, \delta, \rho)$. We choose the parameter $\rho=0.285$, corresponding to an elasticity of substitution elasticity between unskilled and skilled labor of $\frac{1}{1-\rho}=1.4$, as estimated by Katz and Murphy (1992); see also Borjas (2003). In order to evaluate the importance of general equilibrium wage effects we also study a version of the model in which both types of labor are perfect substitutes, $\rho=1$, and thus $\frac{1}{1-\rho}=\infty$. In this case a change in the relative supply of college-educated labor, $\frac{L_{c}}{L_{n}}$, will have no impact on its relative price, $\frac{w_{c}}{w_{n}}$. In appendix 3.2 we show that when moving from the imperfect to the perfect substitution case we do not have to recalibrate any of the other parameters (apart from a TFP scaling factor in the production function) for the model to attain the same steady state statistics.

The capital share is set to $\alpha=1 / 3$. Furthermore we target an investment to output ratio of $20 \%$ and a capital-output ratio of 2.65 as in Fernandez-Villaverde and Krueger (2011) who measure capital as the sum of private nonresidential fixed assets, private residential structures and consumer durable goods from NIPA. Accounting for population growth this implies a yearly depreciation rate of $7.55 \%$ and thus a yearly interest rate of about $5.4 \%$. The capital-output ratio (equivalently, the real interest rate) will be attained by appropriate calibration of the preference parameters (especially the time discount factor $\beta$ ), as discussed below. 


\subsection{Government Policy}

In the initial steady state the policy parameters to be chosen are $\left(\tau_{k}, \tau_{l}, \tau_{c}, \tau_{p}, d, b, g y\right)$. We pick $b=0.6$ and $g y=0.17$ to match a government debt to GDP ratio of $60 \%$ and government consumption (net of tertiary education expenditure) to GDP ratio of $17 \%$. Consumption taxes can be estimated from NIPA data as in Mendoza, Razin and Tesar (1994) who find $\tau_{c} \approx 0.05$. For the capital income tax rate, we adopt Chari and Kehoe's (2006) estimate of $\tau_{k}=28.3 \%$ for the early 2000's.

The payroll tax $\tau_{s s}=12.4 \%$ is chosen to match the current social security payroll tax (excluding Medicare). We model social security benefits $p_{t, j}(e, s)$ as a concave function of average wages earned during a household's working life, in order to obtain a reasonably accurate approximation to the current progressive US benefit formula, but without the need to add a continuous state variable to the model. The details of the calibration of social security benefits are contained in appendix 3.1.

We calibrate the labor income tax deduction to match the sum of standard deductions and exemptions from the US income tax code. Both median income as well as the size of the standard exemption and deduction varies by household size and type, but their ratio is roughly constant at $35 \%$. Thus we calibrate the deduction in the benchmark economy to $35 \%$ of the (endogenous) median income in the model. That is, we choose the policy parameter $d$ such that $\frac{d \cdot Y / N}{m e d\left(y^{\text {gross }}\right)}=35 \%$, where $Y / N$ is output per capita in the model. ${ }^{32}$ Finally the marginal tax rate on labor income $\tau_{l}$ is chosen to balance the government budget. ${ }^{33}$

32 In 2009, according to the U.S. Census Bureau Statistical Abstract of the United States 2012 (table 692), median household money income of a household of 4 members was $\$ 73,071$, relative to a sum of standard deduction $(\$ 11,400)$ and four times the exemption $(4 \cdot 3,650)$ of $\$ 26,000$. The corresponding numbers for a two person household are $\$ 53,676$ and $\$ 18,700$ and for a single person of $\$ 26,080$ and 10,350 . The corresponding ratios are $d=35.6 \%, d=34.8 \%$ and $d=35.9 \%$.

We approximate money income in the model as

$$
y^{\text {gross }}(0, j, \gamma, s, \eta)=(a+T r) \cdot r+\left(1-0.5 \tau_{s s, 1}\right) w_{0, s} \epsilon_{j, s} \gamma \eta l
$$

with social security contributions by the employer not part of the measure of income to which we relate the size of the deduction.

33 Alternatively we could have chosen $\left(d, \tau_{l}\right)$ such that the model matches the relative dispersionmeasured, e.g., by the variance of logs—of pre-tax and disposable income. Using the tax function estimates reported in Heathcote et al. (2014) gives an empirical target of 0.72, whereas our model implies a value of 0.86 , suggesting that our simple benchmark tax system misses progressivity at higher income. Matching this statistic would have required $\left(d=0.37, \tau_{l}=0.32\right)$ and thus a more progressive tax system. Note that this alternative choice of the status quo does not affect, abstracting from recalibration of the other parameters, the determination of the optimal tax system. 


\subsection{Preferences}

The bequest parameter $v$ is chosen so that in equilibrium total transfers-i.e., the sum of inter-vivo transfers and accidental bequests-in the economy account for $1.7 \%$ of wealth as in the 1986 SCF (summarized by Gale and Scholz, 1994). We specify the period utility function as

$$
u(c, l)=\frac{\left[c^{\mu}\left(1-\mathbf{1}_{s} \xi(e)-l\right)^{1-\mu}\right]^{1-\sigma}}{1-\sigma} .
$$

We a priori choose $\sigma=4$ and then determine the time discount factor $\beta$ and the weight on leisure $\mu$ in the utility function such that in the benchmark model the capital-output ratio is 2.65 and households on average work $1 / 3$ of their time. ${ }^{34,35}$

\subsection{Education Costs and Subsidies}

We choose the resource cost for college education $\kappa$ and the share of expenses borne by the government and private sources, $\theta$ and $\theta_{p r}$, in the benchmark model to match the total average yearly cost of going to college, as a fraction of GDP per capita, $\frac{\kappa w_{c}}{\bar{y}}$, and the cost net of subsidies, $\frac{\left(1-\theta-\theta_{p r}\right) \kappa w_{c}}{Y / N}$.

To calculate the corresponding numbers from the data we turn to Ionescu and Simpson (2014) who report an average net price (tuition, fees, room and board net of grants and education subsidies) for a four year college (from 2003-04 to 2007-08) to be $\$ 58,654$ and for a two year college of $\$ 20,535$. They also report that $67 \%$ of all students that finish college completed a 4 year college and $33 \%$ a two year college. Thus the average net cost of tuition and fees for one year of college is

$$
0.67 \cdot 58,654 / 4+0.33 \cdot 20,535 / 2=\$ 13,213 .
$$

Average GDP per capita during this time span was, in constant 2005 dollars, $\$ 42,684$. Thus

$$
\frac{\left(1-\theta-\theta_{p r}\right) \kappa w_{c}}{Y / N}=13,213 / 42,684=0.31 .
$$

Furthermore education at a glance (OECD 2012, Table B3.2b) reports that the share of tertiary education expenditures borne by public and private subsidies is $\theta=38.8 \%$

34 These preferences imply a Frisch elasticity of labor supply of $\left(\frac{1-\mu(1-\sigma)}{\sigma}\right)\left(\frac{1-l}{l}\right)$, and with an average labor supply of $l=1 / 3$ one could be worried that the Frisch labor supply elasticity, which, given the parameter estimates will be around 1 for most households, is implausibly high. But note that this elasticity of labor supply of entire households, not that of white prime age males on which many lower empirical estimates are based. Also, the average Frisch elasticity for households in the age bin 24-54 in our model is at 0.6 which we view as a conservative estimate.

35 The coefficient of relative risk aversion with this formulation equals $\sigma \mu+1-\mu \approx 2$. 
and $\theta_{p r}=16.6 \%$, so that

$$
\frac{\kappa w_{c}}{Y / N}=\frac{0.31}{1-\theta-\theta_{p r}}=0.694
$$

Thus the cost parameter $\kappa$ is calibrated so that the equilibrium of the benchmark model has $\frac{\kappa w_{c}}{Y / N}=0.694$.

\subsection{Ability Transitions and College Time Costs}

Newly formed households draw their ability from a distribution $\pi\left(e \mid s_{p}, \gamma_{p}\right)$ whose mean $\mu\left(s_{p}, \gamma_{p}\right)$ depends on the education level $s_{p}$ and permanent labor productivity $\gamma_{p}$ of their parents; recall that the distribution of the latter is in turn determined by parental ability $e_{p}$. We interpret $e \in[0,1]$ as basic ability to succeed in college and in the labor market. We assume that $e$ follows a normal distribution with mean $\mu\left(s_{p}, \gamma_{p}\right)$ and standard deviation $\sigma_{e}$, truncated to the unit interval, that is, for all $e_{p} \in[0,1]$

$$
\pi\left(e \mid s_{p}, \gamma_{p}\right)=\frac{\psi\left(\frac{e-\mu\left(s_{p}, \gamma_{p}\right)}{\sigma_{e}}\right)}{\Psi\left(\frac{1-\mu\left(s_{p}, \gamma_{p}\right)}{\sigma_{e}}\right)-\Psi\left(\frac{-\mu\left(s_{p}, \gamma_{p}\right)}{\sigma_{e}}\right)},
$$

where $\psi$ is the pdf of a standard normal and $\Psi$ is the cdf of a standard normal. Note that both the numerator as well as the denominator is dependent on $\mu\left(s_{p}, \gamma_{p}\right)$. By assuming that

$$
\mu\left(s_{p}, \gamma_{p}\right)= \begin{cases}0.5-\chi+\zeta \mathbf{1}_{\mathbf{s}_{\mathbf{p}}=\mathbf{c}} & \text { for } \gamma_{p}=\gamma_{l, s_{p}} \\ 0.5+\chi+\zeta \mathbf{1}_{\mathbf{s}_{\mathbf{p}}=\mathbf{c}} & \text { for } \gamma_{p}=\gamma_{h, s_{p}}\end{cases}
$$

the distribution of ability is characterized by three parameters $\chi, \zeta, \sigma_{e}$ where $\chi$ measures the impact of parental ability on children's ability, whereas $\zeta$ captures the importance of parental education. We choose $\chi$ to fit the intergenerational persistence of earnings in the data, $\zeta>0$ to match college completion rates conditional on parental education $s=c$ (that is, to match intergenerational persistence in education) and $\sigma_{e}$ such that $95 \%$ of the probability mass of the $e$-distribution lies in the unit interval $e \in[0,1]$.

Note that this parametrization of the intergenerational ability transmission gives both a role to parental education and to parental ability (through their draws of $\gamma$ ) for shaping children's ability $e$. We then restrict $e$ to take on a discrete set of $n_{e}=31$ values that are evenly spaced in the unit interval. ${ }^{36}$ Based on their ability $e$ the time requirement for attending class and studying in college is given by the function

$$
\xi(e)=\exp (-\lambda e)
$$

36 We do not directly target intergenerational ability persistence. Our calibration implies model intergenerational ability persistence of 0.22 . The ability persistence appears to be somewhat lower than in the data, cf. Abbott, Gallipoli, Meghir and Violante (2013). 
where $\lambda>0$ is a parameter that governs the importance of ability $e$ for the time (and thus utility) cost of going to college. We calibrate $\lambda$ to match the overall share of households completing college in the data.

To obtain college completion rates of students by parental education we turn to the National Education Longitudinal Study (NELS:88). ${ }^{37}$ We compute the percent of individuals from this nationally representative sample who were first surveyed as eighthgraders in the spring of 1988, that by 2000 had obtained at least a Bachelors degree, conditional on the highest education level of their parents. We identify $s_{p}=c$ in our model with the highest education of a parent being at least a Bachelors degree (obtained by 1992). We find that for students with parents in the $s_{p}=c$ category $63.3 \%$ have completed a Bachelors degree. The corresponding number for parents with $s_{p}=n$ is $28.8 \%$.

\subsection{Borrowing Constraints}

The borrowing constraints faced by agents pursuing a college degree allow such an agent to finance a fraction $\phi \in[0,1]$ of all tuition bills with credit. We specify a constant (minimum) payment $r p$ such that at the age of retirement all college loans are repaid. Formally

$$
\underline{A}_{j a, t}=\phi\left(1-\theta_{t}-\theta_{p r}\right) \kappa w_{t, c} .
$$

and for $j=j_{a}+1, \ldots, j_{r}$ :

$$
\underline{A}_{j, t}=\left(1+r_{t}\right) \underline{A}_{j-1, t-1}-r p
$$

and $r p$ is chosen such that the terminal condition $\underline{A}_{j_{r}, t}=0$ is met.

The parameter $\phi$ to be calibrated determines how tight the borrowing constraint for college is. Note that in contrast $r p$ is not a calibration parameter but an endogenously determined repayment amount that insures that households do not retire with outstanding student loans.

The maximum amount of publicly provided student loans for four years is given by $\$ 27,000$ for dependent undergraduate students and $\$ 45,000$ for independent undergraduate students (the more relevant number given that our students are independent households). ${ }^{38}$ Relative to GDP per capita in 2008 of $\$ 48,000$, this given maximum debt constitutes $14 \%$ and $23.4 \%$ of GDP per capita. Compare that to the $31 \%$ of total costs computed above, this indicates that independent undergraduate students can borrow at most approximately $75 \%$ of the cost of college, and thus we set $\phi=0.75$. The justification for our choice of $\phi$ again clarifies that it should best be thought of as an education policy parameter that is being held fixed in our optimal policy analysis. Table 2 above summarizes the parameters used in our optimal tax computations.

37 http://nces.ed.gov/surveys/nels88/

38 Note that about $66 \%$ of students finishing four year colleges have debt, and conditional on having debt the average amount is $\$ 23,186$ and the median amount is $\$ 20,000$. 


\section{Results}

In this section we present our results. We first discuss what determines the education decision in the initial steady state; since that steady state is identical across the perfect and imperfect substitutability case no distinction is needed. We then turn to the determination of the optimal tax-subsidy policy showing that considering transitional dynamics and general equilibrium wage effects are crucial for the normative policy analysis. Finally we discuss the sources of the welfare gains from the optimal policy, relative to the initial status quo.

\subsection{How the Model Works: The Education Decision}

Prior to presenting the optimal tax results it is instructive to discuss how households make their key economic decisions for a given policy. Ours is a fairly standard life cycle model with idiosyncratic wage risk, and thus the life cycle profiles of consumption, asset and labor supply are consistent with those reported in the literature (see e.g. Conesa et al. (2009), figure 1). Instead, here we explore how the optimal education decision is made, as a function of the initial characteristics of the household. This focus is further warranted by the observation that the optimal policy will have a strong impact on this decision and will result in a significant change in the share of households obtaining an education in the aggregate, which is in turn important for understanding the optimality of the policy in the first place.

Recall that households, at the time of the college decision (that is, at age $j_{a}$ ) differ according to $(e, \eta, b)$, that is, their ability to go to college $e$, their wages outside college (as determined by the idiosyncratic shock $\eta$ ), and their initial asset levels resulting from parental transfers $b$. In figure 2 we display the share of households deciding to go to college, under the status quo policy, as a function of $e$, both for households with low and with high $\eta$ realizations. All households with high abilities $\left(e \geq e_{22}\right)$ go to college, and non of the households with very low ability $\left(e \leq e_{10}\right)$ do. For households in the middle of the ability distribution, their decision depends on the attractiveness of the option of working in the labor market: a larger share of households with lower opportunity costs (low $\eta$ ) attends college. Finally, a share strictly between zero and one, conditional on $\eta$, indicates that heterogeneity in wealth $b$ among the youngest cohort (which in turn stems from wealth and thus transfer heterogeneity of their parents) is an important determinant of the college decision for those in the middle of the ability distribution $\left(e \in\left[e_{11}, e_{21}\right]\right)$.

This point is further reinforced by figure 3 which displays the college decision indicator function in dependence of initial assets $b$, and conditional on the non-college wage realization $\eta$. A value of 0 on the $y$-axis stands for not attending college, a value of 1 represents the decision to go to college. Assets on the $x$-axis are normalized such that a value of $b=1$ stands for assets equal to one time average asset holdings of the 
parental generation at the age intergenerational transfers are given. We display the policy function for those with relatively low ability $\left(e=e_{17}\right)$ and those with relatively high ability $\left(e=e_{25}\right)$.

We make several observations. First, and not surprisingly, lower-ability households go to college for a smaller range of initial assets than do high ability households. Second, as discussed above, a higher non-college wage reduces the incidence of attending college. Finally and perhaps most interestingly, the effects of initial wealth on the college decision are non-monotone. For households at the low end of the wealth distribution (and with sufficiently low e) the borrowing constraint is important. Although the government subsidizes college (in the status quo it covers a 38.8\% share of the costs) and although households can borrow $75 \%$ of the remaining resource costs, at zero or close to zero wealth a household might still not be able to afford college. That is, either it is impossible for these households to maintain positive consumption even by working full time while attending college, or the resulting very low level of consumption and/or leisure make such a choice suboptimal. As parental transfers $b$ increase the borrowing constraint is relaxed and even the less able households decide to go to college. Finally, sufficiently wealthy households that expect to derive a dominant share of their lifetime income from capital income find it suboptimal to invest in college and bear the time and resource cost in exchange for larger labor earnings after college. Note, however, that although this last result follows from the logic of our model, it is not important quantitatively since the stationary asset transfer distribution puts essentially no mass on initial assets $b \geq 5$.

\subsection{Analysis of Optimal Policy Transitions}

We now document our main optimal policy results, proceeding in three steps. First, in the next subsection, we summarize the optimal fiscal constitution for our benchmark economy when both transitional dynamics and general equilibrium relative wage effects are taken into account in the analysis. Then, in the following two subsections, we aim at providing intuition for the results by first analyzing the optimal steady state pol$i c y$ in the absence of relative wage movements (section 6.2.2), and then documenting the quantitative importance of transitional dynamics in section 6.2.3. 


\subsubsection{The Optimal Policies}

Table 3 displays the optimal policy combinations, both for maximizing steady state and transitional welfare. ${ }^{39}$ In addition, the table provides summary measures of aggregate economic activity ${ }^{40}$ and inequality statistics for the initial steady state with status quo policy (column 2), and the final state of the optimal policy induced transition (column 3). Column 4 shows the change in these variables between the initial and the final steady state. ${ }^{41}$ Finally, columns 5 and 6 do the same, but for the optimal steady state policy that ignores transitional dynamics and hence transitional welfare. ${ }^{42}$

The first five rows of table 3 display the fiscal constitution in the economy, both in the initial steady state as well as in the social optimum. Recall that $\tau_{l}$ is the marginal labor income tax rate, $\theta$ the public subsidy rate, $Z=d \frac{Y}{N}$ is the size of the labor income tax deduction and $d$ measures the size of the deduction relative to income per capita. They show that (see columns 3 and 4 of the table ${ }^{43}$ ), starting from the status quo, the optimal policy transition is obtained by a significantly larger education subsidy of $150 \%$ and a significantly less progressive tax system. The deduction $d$ falls from $27 \%$ to $6 \%$ of average income, and thus the optimal tax system, when combined with a generous education subsidy, is not far away from a proportional labor income tax system. The welfare gains from the optimal policy transition, relative to the status quo are substantial, in the order of $3.5 \%$ of lifetime consumption.

In order to start understanding where these welfare gains emerge from we turn to the remaining rows of table 3 and figure 4 , which collects the transitional dynamics of key macroeconomic aggregates induced by the optimal policy reform.

The upper left panel of figure 4 displays both the share of the youngest cohort going to college as well as the overall fraction of the population. It shows that the increase in the college subsidy and the reduction in marginal (and average) tax rates for high income earners induces a college boom on impact. The share of the youngest cohort completing college rises from $44 \%$ in the initial steady state to about $67 \%$ in the first

39 In order to meaningfully compare the optimal steady state policies and the optimal transition policies we adopt the same type of welfare criterion when maximizing steady state welfare as when maximizing transitional welfare: the integral of lifetime utilities, weighted by the cross-sectional distribution of state variables in the intitial steady state. In contrast to maximizing expected utility of a newborn household (as often done in the literature, see e.g. Conesa et al., 2009), this welfare measure places positive weight on older households even in the steady state.

40 All variables are denoted in per capita terms.

41 For variables that are already in \% units we report the percentage point changes. For the Gini coefficients we simply report the point changes.

42 When characterizing optimal steady state policies we hold constant the government debt to GDP ratio at its initial steady state level.

43 We will return to the optimal steady state results in columns 5 and 6 below. 
period of the policy transition. ${ }^{44}$

The second observation we make from the upper left panel is that the share of college bound youngsters is falling over time. The reason for this reduction is displayed in figure 5 which shows wages of college and non-college households relative to their initial steady state levels. From the figure it is clear that the college wage premium decreases substantially over time. ${ }^{45}$ Consequently the college boom lessens over time, although the share of young cohorts going to college remains about $23 \%$ (or about $10.5 \%$ points) above its initial steady state level. As a consequence, as we will show in sections 6.2.2 and 6.2.3, the skill distribution improves much less pronouncedly in the economy with general equilibrium relative wage effects, compared to the economy in which this effect is absent.

Third, whereas the share of the youngest cohort going to college increases immediately by close to $60 \%$ on policy impact, it takes approximately two generations (roughly 60 years) until the overall skill distribution has reached a level close to its new steady state value. It is this sluggish dynamics of the skill and thus labor productivity distribution that a restriction to a long-run steady state policy analysis would miss completely.

The trends in educational attainment and thus average labor productivity are reflected in aggregate output and consumption, as figure 4 and table 3 show. First, focusing on the long run steady state, the optimal policy reform has a strong long-run positive effect on output and consumption per capita ( $8 \%$ and $10.3 \%$ in table 3$)$, despite the fact that hours worked only move moderately (by $1.3 \%$ points) in response to the lower marginal labor income taxes. Nevertheless labor efficiency units per person $\frac{L}{N}$ increase drastically (by $7.7 \%$ ) in the new, relative to the old steady state, on account of a more skilled workforce.

However, as discussed above, the skill distribution evolves slowly. The upper right and the lower left panel of figure 6 show the corollary of this result: as the skill distribution improves only slowly and more and more on average more skilled cohorts enter the labor force over time, effective labor units supplied and output per capita (upper right panel) increase slowly along the transition as well. The lower right panel documents the same for consumption, and also shows that average hours worked increase on impact by about $3 \%$ (1.3\% points) because of the decline in the marginal tax rate $\tau_{l}$. This is true despite the fact that a larger share of the youngest age cohort now

44 We also observe a further discrete upward jump in the share of the newborn cohort attending college 30 years after the initial policy reform. The distribution of ability of children is partially determined by the persistence of innate ability, but also impacted by parental education. The boost of college attendance on impact generates more highly educated parents thirty years later, and thus a more favorable college ability distribution which in turn makes a higher share of children attend college themselves. Further, but smaller, echo effects are observed for later generations.

45 Also note that, at least in the long-run, the overall wage level per efficiency unit of labor increases moderately, see table 3. In consequence, absolute wages of the unskilled increase and this increases is stronger than the fall of wages of the skilled. 
goes to college and thus withdraws temporarily from the labor force. ${ }^{46}$

Finally, the lower right panel of figure 6 displays the evolution of government debt per capita and the debt-to-output ratio. Given the tax and education policy and the initial debt level the sequence of government debt is determined from the sequence of period government budget constraints. The government finds it optimal (through the setting of $\left.\tau_{l}, \theta, d\right)$, to smooth the transitional costs of building up a higher human capital stock (i.e., high education policy costs and relatively lax revenues due to low-relative to the final steady state-economic activity) by borrowing along the transition. As a consequence the debt to output ratio increases from $60 \%$ to $80 \%$ (an increase of about $20 \%$ percentage points, or $33 \%$ ) along the transition. Debt per capita is increasing more strongly than that since GDP is also increasing along the transition, although not at the same speed as debt itself, which explains the increase in the debt to GDP ratio.

On the distributional side, consumption and wealth inequality fall despite the reduction in the labor income tax progressivity. This is mainly due to the fact that in the final steady state there are significantly less consumption- and wealth poor unskilled households. Furthermore, the college wage premium shrinks significantly in response to the policy reform, further aiding the decline in consumption inequality. Overall, and to summarize, the policy reform increases educational attainments, raise output and consumption per capita significantly both in the short and in the long run on account of a more productive workforce and at the same time reduces consumption inequality on account of a narrowing college wage premium, despite the fact that the tax system has become less redistributive. ${ }^{47}$ In the next subsections we document the importance of the general equilibrium wage effects as well as an explicit consideration of the transitional dynamics for this finding.

\subsubsection{The Importance of General Equilibrium Relative Wage Effects}

In table 4 we summarize the optimal policy reforms and associated aggregate and distributional consequences in an economy where skilled and unskilled labor are perfect substitutes but all other model parameters remain unchanged. ${ }^{48}$

Comparing first the optimal steady state policies (column 5 and 6 in both tables 3 and 4) between the benchmark economy and the perfect substitutes case reveals the importance of the general equilibrium wage effects for optimal policy design. Whereas the optimal education subsidy is similarly large in both cases (and substantially larger

46 College students can and do work while studying, but the hours they supply are quantitatively minor.

47 Hours worked increase slightly and hours (and thus leisure) inequality rises somewhat, but both effects are quantitatively rather modest.

48 Recall that appendix 3.2 demonstrates that by simply scaling the aggregate TFP parameter we can insure that this version of the model attains the same aggregates in the initial steady state as the benchmark economy 
than in the initial status quo) the degree of tax progressivity differs fundamentally. In the benchmark economy where redistribution across different ability $e$ types and thus across eduction groups can be achieved through the general equilibrium wage effects induced by the education subsidies, a strongly progressive tax system is not desirable even in the steady state: $d=10 \%$ is optimal, relative to the benchmark of $d=27 \%$. If education policies stimulating college attendance do not affect the college wage premium as in the perfect substitutes case, instead a strongly progressive tax system with a deduction worth $31 \%$ of average income (and thus more progressive than the status quo) is optimal when the government is maximizing steady state welfare.

From table 4) we observe that the steady state optimal policy change reduces hours worked in the steady state substantially (by $2.75 \%$ points, or $8.4 \%$ ). However, absent the reduction in the college wage premium the education boom is so massive that labor input as well as output and consumption per capita rise substantially. The reduction in consumption inequality and the welfare gains are similar between the steady states in the imperfect substitutes case and the perfect substitutes case, but they are achieved with different tools: in the latter case, since relative wages don't move by construction, redistribution has to be achieved via the income tax code, as a deduction of $d=31 \%$ (relative to $d=10 \%$ in the benchmark) shows. This in turn has severe consequences for the importance of the transitional dynamics in optimal policy design, as the next subsection will demonstrate.

\subsubsection{Transitional Dynamics}

As already discussed in the benchmark case, it takes time (and resources) to build up a more skilled workforce, suggesting that an explicit consideration of the transition path is important. Comparing the optimal policy transition and the steady state optimal policy (columns 3 and 5 of table 4) strongly reinforces this point. Explicitly taking into account the transitional costs, the optimal tax code should become less, not more progressive. This raises two questions, a) why is there such a divergence between steady state optimal and dynamically optimal policies? and b) why doesn't this divergence show up in the benchmark version of the model (compare columns 3 and 5 of table 3)?

The answer to the first question is contained in figures 6, displaying the evolution of macroeconomic aggregates in the perfect substitution case under the transitionoptimal policy and showing monotonically increasing aggregate consumption, and figure 7 which shows the transition path for consumption for different policy combinations. We see in figure 7 how the economy goes through a recession if the decrease of taxes and the reduction of the tax deduction would not have taken place when the education subsidy is increased $(d=0.27, \theta=1.2)$. As households are drawn from the labor market into college, the economy experiences a transitional decline in output and per capita consumption. The figure also shows the outcome along the transition if the government would implement the optimal steady state policy combination 
$(d=0.31, \theta=1.7)$. In this case the recession is even more severe because the subsidy is substantially higher and so are marginal labor income taxes and the tax deduction. ${ }^{49}$

Table 5 summarizes the associated welfare consequences from the policy reform. With the increase of the tax subsidy alone, there are still welfare gains, but they are much smaller than in the optimum. An implementation of the optimal steady state policy instead leads to substantial welfare losses along the transition. These findings represent our first main result perhaps most clearly: an explicit consideration of the transition path when conducting a normative welfare analysis of education and tax policies can change even the qualitative prescriptions for optimal fiscal policy dramatically.

This finding raises the second question: why doesn't the same logic apply also to the benchmark economy, where, as columns 3 and 5 of table 3) show, there is no strong divergence between steady state and transition-optimal policies. In the next section we argue that the answer lies in the fact that the general equilibrium wage effects allow the government to achieve effective redistribution through education subsidies. Therefore a high degree of tax progressivity (as embedded in a high deduction $d$ ) is not required to achieve a less dispersed consumption distribution even in the steady state.

\subsubsection{Progressive Income Taxation and Education Subsidies: Complements or Sub- stitutes?}

In this subsection we stress the importance of the general equilibrium wage response to fiscal policy and explore its role further. As one summary measure, recall that the welfare gain of switching to the optimal policy $(d=0.06, \theta=1.5)$ in the benchmark economy was $3.5 \%$ (see column 4 , last row in table 3 ). In comparison, the welfare gain of this same policy reform in the economy with perfect substitutes (and thus absent general equilibrium wage effects) is only $1.61 \%$, close to the gain of $1.66 \%$ from the optimal reform in this economy (see column 4 , last row in table 4 ). Thus the general equilibrium response, especially the reduction of the college wage premium, is very important for the welfare assessment of the optimal policy.

In the simple model in the appendix we demonstrate how progressive taxes and education subsidies can be complementary second best policies in a world where private insurance is imperfect, and thus public insurance is potentially beneficial but distorts human capital accumulation decisions, with education subsidies mitigating this distortions. This model (and indeed the quantitative model with perfect substitutability of labor) abstracted from the general equilibrium relative wage effects induced by these policies which curbs the effectiveness of education subsidies for encouraging college attendance. With the two types of labor being imperfect substitutes, the education pol-

49 Interestingly, the long-run increase of per capita consumption is smaller than in the steady state comparison. Taking the transition into account when implementing the optimal steady state policy leads to a long-run increase of per capita consumption by only about $2 \%$ whereas the last column of table 4 shows an increase of about $5 \%$. 
icy now has indirect beneficial redistributive effects, by reducing the average wage gap between skilled and unskilled workers, and thus might potentially be a substitute for redistributive tax policies in general equilibrium.

To explore this theme further we compute optimal policies along one policy dimension, holding the other dimension constant. We restrict ourselves to steady states to make our points most clearly. Table 6 presents results for the perfect substitutes economy in the left part which is easiest to interpret. The first column restates findings already familiar from table 4 . The next two columns document results for constrained-optimal policies when one instrument (either the education subsidy $\theta$ or the size of the deduction $d$ is held constant. The univariate optimization over $d$ delivers the same optimal degree of tax progressivity according to this measure $(d=0.31)$. However, comparing the alternative measures for the progressivity of the income tax code, $Z$ as well as $\tau_{l} \cdot Z$, for the full optimum (column 2) with the constrained optimum (column 4) where we hold $\theta$ constant, we observe the complementarity of policy instruments also documented in the simple model in the Appendix in table 1 and stressed by Bovenberg and Jacobs (2005). When $\theta$ is fixed at its status quo value of $\theta=38.8 \%$, which is lower than the full steady state optimum of $\theta=170 \%$, the constrained optimal effective tax deduction (as measured either by $Z$ or $\tau_{l} Z$ ) is lower as well.

Table 6 also shows that most of the (steady state) welfare gains stem from an adjustment of the education subsidy: the best steady state policy reform brings welfare gains of $2.6 \%$ of lifetime consumption, and only adjusting the education subsidy generates almost the same welfare gains of $2.5 \%$ (since the optimal tax progressivity is close to the status quo), whereas adjusting the progressivity of the labor income tax code alone yields only gains of $0.17 \%$ (since the optimal education subsidy is much larger than the status quo). Of course, absent general equilibrium wage effects the education policy is very effective in stimulating college attendance and thus labor productivity in the long run; along the transition this policy is not nearly as beneficial, which also explains why the transitional welfare gains are lower than the long-run benefits, compare the last row of columns 4 and 6 of table 4 .

The right part of Table 6 repeats the same decomposition exercise for the imperfect substitutes case with general equilibrium wage effects. Interestingly, we observe that the univariate optima favor a higher degree of tax progressivity and education subsidies, just as for the case with perfect substitutes. However, once both policy instruments are in operation, the two instruments become substitutes: in the unconstrained optimum, the degree of education subsidies is higher than in the univariate optimum and tax progressivity decreases. Now the additional effect of a decrease of the college wage premium allows the government to achieve a more equal consumption distribution (at least across college- vs. non-college households) either through college education subsidies or progressive income taxes. Also, in this case transitional welfare gains are larger than long-run welfare gains since the GE wage reactions only play out in the long-run and reduce college attendance. 
We conclude this section by summarizing our second main finding: whether the two policies complement each other or become substitutes in providing redistribution crucially depends on the importance of general equilibrium effects. Since we find the empirical evidence for imperfect substitutability of skilled and unskilled labor compelling we conclude that the case for education subsidies and progressive labor income taxes being substitutable policies is strong.

\subsection{Sensitivity Analysis}

\subsubsection{Restrictions on the Policy Space}

In order to render our analysis computationally feasible we studied simple policy instruments and restricted them to be constant along the transition path. In this subsection we explore the question whether our results are driven by these restrictions.

Quantitatively, the most prominent finding is the optimality of large education subsidies. These subsidies transfer resources to young households for going to college. Here we briefly ask whether this policy is welfare improving simply because it provides intergenerational redistribution towards young, potentially credit-constrained households. If this were the case, then unconditional transfers that are not contingent on college attendance should lead to similar or even larger welfare gains. Restricting ourselves to steady-state optimal policies ${ }^{50}$ we find an optimal policy combination of $d=10 \%$ and $\theta=160 \%$, with welfare gains of $1 \%$ instead of $2.76 \%$. That is, substantial lump-sum transfers to the young remain optimal, but they are less effective in improving social welfare since they are not targeted at college attendees which stimulates less college attendance. ${ }^{51}$ The share of college youngsters increases to $49 \%$ only instead of $58.6 \%$. This reduces the college wage premium by less (it falls only by $14.4 \%$ instead of $28.1 \%$ ) which is the key source of the welfare gain according to our baseline results. We conclude that making transfers to the young less education-targeted is not beneficial. $^{52}$

Second, we study whether the government forgoes important welfare gains by not phasing in the policy reforms more slowly, permitting time-varying fiscal and educa-

50 Which in any case do not deviate much from the transition-optimal policies in the benchmark economy with imperfect substitutability of labor.

51 The optimal education-contingent policy makes borrowing constraints irrelevant for the education allocation, as the share of college attendants is invariant to the tightness $\phi$ of the borrowing constraint if education subsidies are set to $\theta=150 \%$

52 On the other hand we need to acknowledge that policies that make education subsidies parental income- or wealth specific or condition them (if feasible) directly on student ability are likely to do even better, since our policy subsidizes even students that would have gone to college in any case. Findeisen and Sachs (2015), for example, find that the Pareto optimal policy in their model is characterized by income-contingent student loans. 
tion policies. To do so we now consider transitional policies of the form

$$
\begin{aligned}
\tau_{l, t} & =e^{-\omega(t-1)} \tau_{l, 0}+\left(1-e^{-\omega(t-1)}\right) \tau_{l, T} \\
\theta_{t} & =e^{-\omega(t-1)} \theta_{0}+\left(1-e^{-\omega(t-1)}\right) \theta_{T} \\
d_{t} & =e^{-\omega(t-1)} d_{0}+\left(1-e^{-\omega(t-1)}\right) d_{T}
\end{aligned}
$$

where $\left(\tau_{l, 0}, \theta_{0}, d_{0}\right)$ is the calibrated policy in the initial steady state and $\left(\tau_{l, T}, \theta_{T}, d_{T}\right)$ is an arbitrary time constant new policy, and $\omega \in[0, \infty)$ is a parameter that governs the speed of adjustment. If $\omega=\infty$ then adjustment is immediate; this is the assumption we make in the paper. The smaller is $\omega$, the more gradual the new policy is being introduced. Using this structure we ask two related questions:

1. Is it optimal to more gradually introduce the policy we found to be optimal along the transition? To answer this question we take $\left(\tau_{l, T}, \theta_{T}, d_{T}\right)=\left(\tau_{l}^{*}, \theta^{*}, d^{*}\right)$ and maximize social welfare with respect to $\omega$. The answer we found is, to a very good approximation $(\omega=4)$, there is no benefit from introducing the optimal policy more gradually. In this (limited) sense results are robust towards permitting time variation in the policy instruments.

2. Is the suboptimality of the policy that maximizes steady state welfare along the transition due to the fact that it is introduced too rapidly? We now take the steady-state optimal policy $\left(\tau_{l, T}, \theta_{T}, d_{T}\right)=\left(\tau_{l}^{S S}, \theta^{S S}, d^{S S}\right)$ and again maximize social welfare with respect to $\omega$. Now the answer is, yes, the steady state optimal policy leads to larger welfare gains along the transition if it is introduced more slowly and phased in over a time interval of about 16 years. ${ }^{53}$

\subsubsection{Alternative Parameterizations}

Our model contains many parameters that determine the quantitative magnitudes of the optimal policies. We have documented the importance of the degree of substitutability of skilled and unskilled labor for the results. Our choice of substitution elasticity for the case with imperfect substitutes was 1.4, based on the conventional estimates by Katz and Murphy (1992) or Borjas (2003). According to Card (2009) an alternative reasonable estimate is 3.33, i.e., a value of $\rho$ of 0.7 . We recompute the optimum with such an alternative calibration for the steady state comparison with imperfect substitutes. We find that the optimal education subsidy $\theta$ falls from $200 \%$ to $190 \%$, and tax progressivity as measured by $d$ goes up from $10 \%$ to $16 \%$. The optimal labor income tax rate is $28.8 \%$ instead of $26 \%$. Results are thus in between the benchmark and perfect substitutes case, but quantitatively (and qualitatively) closer to the benchmark.

One key endogenous decision is the education decision, which is shaped by public education policies and private intergenerational transfers. The size of the latter is in turn

53 Of course, the transition-optimal policy still dominates the slowly introduced steady state policy 
determined by $v$, the weight of children's lifetime utility in parental welfare. We calibrated $v$ so that the magnitude of intergenerational transfers in the model is consistent with SCF data in the 1980's. We now investigate whether the optimal large size of public transfers tied to education that we found is sensitive to the magnitude of private transfers induced by a larger $v$. We increase $v$ from 0.48 to 0.6 (and recalibrate all other parameters), inducing inter-vivos transfers to rise by roughly one-third (from $1.1 \%$ to $1.6 \%$ of GDP) in the benchmark economy. Likewise total intergenerational transfers, including accidental bequests, increase from $1.7 \%$ to $2.1 \%$ of GDP. Focusing on steady state optima with imperfect substitutes the new optimum now features a lower degree of tax progressivity ( $d=8 \%$ instead of $d=10 \%$ ) and a higher degree of education subsidies $(\theta=220 \%$ instead of $\theta=200 \%)$ as well as a slightly lower optimal labor income tax rate $\left(\tau^{l}=25.9 \%\right.$ instead of $\tau^{l}=26 \%$ ). Welfare gains increase to $3.62 \%$ (up from $2.76 \%) .{ }^{54}$

\section{Conclusions}

In this paper we characterized the optimal mix of progressive income taxes and education subsidies and argued that a large education subsidy and a moderately progressive labor income tax and constitute part of the optimal fiscal constitution once household college attendance decisions are endogenous and transitional dynamics are modeled explicitly. The latter aspect (transitional dynamics) can have a crucial impact on the optimal policy design, as the case of perfect substitutes indicates. Given the important differences between steady state optimal and transition-optimal policy it is conceivable, in fact likely, that policies that are time-varying over the transition provide further welfare gains. ${ }^{55}$

In our thought experiment we also took the tax on capital income as exogenously given. Future work will need to determine whether our policy conclusions, especially the high subsidy rates for human capital, remain robust once the government chooses not only the progressivity of the labor income tax, but also the optimal mix between capital and labor income taxes.

Finally we determined the optimal tax policy as one which maximizes Utilitarian social welfare among households currently alive. ${ }^{56}$ We also documented that both policy

54 Evaluating welfare with the calibrated value of $v$ of 0.48 gives welfare gains of $3.0 \%$, hence a large part of the increase in welfare is due to the change in the social welfare function caused by recalibrating $v$.

55 Because of the high dimensionality of the policy space these fully time-varying might be hard to characterize numerically for the near future, however.

56 Although Utilitarian social welfare is commonly used in the literature, it is of course but one choice for the social welfare function. For alternative criteria and their merits, see, e.g., Weinzierl (2012) or Saez and Stantcheva (2013). 
instruments are potentially effective in generating more equally distributed consumption and lifetime welfare. We leave for future work a detailed analysis which elements of our optimal fiscal constitution remains intact if social preferences for insurance and redistribution deviate from the Utilitarian benchmark we have analyzed here. 


\section{References}

[1] Abbott, B., G. Gallipoli, C. Meghir and G. Violante (2013), “Education Policy and Intergenerational Transfers in Equilibrium," Working Paper.

[2] Aiyagari, R. (1994), "Uninsured Idiosyncratic Risk and Aggregate Saving," Quarterly Journal of Economics, 109(3): 659-684.

[3] Alvarez, Y., J. Burbidge, T. Farrell, and L. Palmer (1992), "Optimal Taxation in a Life-Cycle Model," Canadian Journal of Economics, 25, 111-122.

[4] Auerbach, A. and L. Kotlikoff (1987), Dynamic Fiscal Policy, Cambridge University Press.

[5] Bakis, O., B. Kaymak and M. Poschke (2014), "Transitional Dynamics and the Optimal Progressivity of Income Redistribution," Review of Economic Dynamics, forthcoming.

[6] Benabou, R. (2002), "Tax and Education Policy in a Heterogeneous-Agent Economy: What Levels of Redistribution Maximize Growth and Efficiency?" Econometrica, 70, 481-517.

[7] Bewley, T. (1986), "Stationary Monetary Equilibrium with a Continuum of Independently Fluctuating Consumers," in Werner Hildenbrand and Andreu MasColell (eds.) Contributions to Mathematical Economics in Honor of Gerard Debreu, North-Holland, 79-102.

[8] Bohacek, R. and M. Kapicka (2008), “Optimal Human Capital Policies,” Journal of Monetary Economics, 55, 1-16.

[9] Bohacek, R. and M. Kapicka (2012), “A Quantitative Analysis of Educational Reforms in a Dynastic Framework," Manuscript, University of California Santa Barbara.

[10] Borjas, G. (2003), “The Labor Demand Curve is Downward Sloping: Reexamining the Impact of Immigration on the Labor Market," Quarterly Journal of Economics, $118,1335-1374$

[11] Bovenberg, L., and B. Jacobs (2005), "Redistribution and Education Subsidies are Siamese Twins," Journal of Public Economics, 89, 2005-2035.

[12] Brown, M., M. Mazzocco, J. Scholz and A. Seshadri (2006), “Tied Transfers," Working Paper.

[13] Card, D. (2009), “Immigration and Inequality," American Economic Review, 99(2), $1-21$. 
[14] Castañeda, A., J. Díaz-Giménez and V. Ríos-Rull (1999), “Earnings and Wealth Inequality and Income Taxation: Quantifying the Trade-offs of Switching to a Proportional Income Tax in the U.S." Working Paper.

[15] Caucutt, E., K. Kumar and S. Imrohoroglu (2006), "Does the Progressivity of Income Taxes Matter for Human Capital and Growth?," Journal of Public Economic Theory, 8, 95-118.

[16] Chamley, C. (1986), "Optimal Taxation of Capital Income in General Equilibrium with Infinite Lives," Econometrica, 54, 607-622.

[17] Chari, V. V., and P. Kehoe (1999), "Optimal Fiscal and Monetary Policy," In Handbook of Macroeconomics, ed. John B. Taylor and Michael Woodford, 1671-1745. Amsterdam: North Holland.

[18] Chari, V. V., and P. Kehoe (2006), "Modern Macroeconomics in Practice: How Theory Is Shaping Policy," Journal of Economic Perspectives, 20, 3-28.

[19] Conesa, J. and D. Krueger (2006), "On the Optimal Progressivity of the Income Tax Code," Journal of Monetary Economics, 53, 1425-1450.

[20] Conesa, J., S. Kitao and D. Krueger (2009), “Taxing Capital: Not a Bad Idea after All!," American Economic Review, Vol 99, 25-48.

[21] Cunha, F., J. Heckman, L. Lochner and D. Masterov (2006), Interpreting the Evidence on Life Cycle Skill Formation, Handbook of the Economics of Education, Vol. 1, 697-812.

[22] Dynarski, S. (2003), "Does Aid Matter? Measuring the Effect of Student Aid on College Attendance and Completion," American Economic Review, 93, 279-288.

[23] Domeij, D. and J. Heathcote (2004), On the Distributional Effects of Reducing Capital Taxes, International Economic Review, 45, 523-554.

[24] Erosa, A. and M. Gervais (2002), “Optimal Taxation in Life Cycle Economies," Journal of Economic Theory, 105, 338-369.

[25] Fehr, H. and F. Kindermann (2015), “Taxing Capital along the Transition - Not a Bad Idea After All?," Journal of Economic Dynamics and Control, 51, 64-77.

[26] Fernandez-Villaverde, J. and D. Krueger (2011), "Consumption and Saving over the Life Cycle: How Important are Consumer Durables? (with J. FernandezVillaverde), "Macroeconomic Dynamics, 15, 725-770.

[27] Findeisen, S. and D. Sachs (2013), "Education and Optimal Dynamic Taxation: The Role of Income-Contingent Student Loans," Working Paper.

[28] Findeisen, S. and D. Sachs (2014), "Designing Efficient College and Tax Policies," Working Paper. 
[29] Fukushima, K. (2010), "Quantifying the Welfare Gains from Flexible Dynamic Income Tax Systems," Working paper, University of Wisconsin.

[30] Garriga, C. (2003), "Optimal Fiscal Policy in Overlapping Generations Models," Working Paper.

[31] Gale, W. and J. Scholz (1994), "Intergenerational Transfers and the Accumulation of Wealth," Journal of Economic Perspectives, American Economic Association, 8, 14560 .

[32] Gervais, M. (2012), "On the Optimality of Age-Dependent Taxes and the Progressive U.S. Tax System," Journal of Economic Dynamics and Control, 36, 682-691.

[33] Greenwood, J, Z. Hercowitz, and G. Hoffman (1988), "Investment, Capacity Utilization, and the Real Business Cycle," American Economic Review, 78, 402-417.

[34] Guvenen, F., B. Kuruscu and S. Ozkan (2014), “Taxation of Human Capital and Wage Inequality: A Cross-Country Analysis," Review of Economic Studies, 81, 818-850.

[35] Heckman, J., L. Lochner and C. Taber (1998), “Tax Policy and Human-Capital Formation," American Economic Review, 88, 293-297.

[36] Heckman, J., L. Lochner and C. Taber (1999), "Human Capital Formation and General Equilibrium Treatment Effects: A Study of Tax and Tuition Policy," Fiscal Studies, 20, 25-40.

[37] Heckman, J., L. Lochner and P. Todd (2006), "Earnings Functions, Rates of Return and Treatment Effects: The Mincer Equation and Beyond," Handbook of the Economics of Education, 307-458.

[38] Heathcote, J., F. Perri and G. Violante (2010), “Unequal We Stand: An Empirical Analysis of Economic Inequality in the United States, 1967-2006," Review of Economic Dynamics, 13, 15-51

[39] Heathcote, J., S. Storesletten and G. Violante (2014), “Optimal Tax Progressivity: An Analytical Framework,"Working paper.

[40] Holmlund, H., M. Lindahl and E. Plug (2011), The Causal Effect of Parents' Schooling on Children's Schooling: A Comparison of Estimation Methods," Journal of Economic Literature, 49, 615-651.

[41] Holter, H. (2014), “Accounting for Cross-Country Differences in Intergenerational Earnings Persistence: The Impact of Taxation and Public Education Expenditure," Working Paper.

[42] Hubbard, G. and K. Judd (1986), "Liquidity Constraints, Fiscal Policy, and Consumption," Brookings Papers on Economic Activity, 1986, 1-50. 
[43] Huggett, M. (1993), “The Risk-Free Rate in Heterogeneous-Agent IncompleteInsurance Economies," Journal of Economic Dynamics and Control, 17, 953-969.

[44] Huggett, M. (1997), "The One-Sector Growth Model with Idiosyncratic Shocks: Steady States and Dynamics," Journal of Monetary Economics, 39, 385-403.

[45] Ionescu, F. and N. Simpson (2014), "Credit Scores and College Investment: Implications for Student Loan Policies," Working paper, Colgate University.

[46] Jacobs, B. and L. Bovenberg (2010), "Human Capital and Optimal Positive Taxation of Capital Income," International Tax and Public Finance, 17, 451-478.

[47] Judd, K. (1985), “Redistributive Taxation in a Simple Perfect Foresight Model," Journal of Public Economics, 28, 59-83.

[48] Judd, K. and C. Su (2006), "Optimal Income Taxation with Multidimensional Taxpayer Types," Working Paper.

[49] Kapicka, M. (2011), "The Dynamics of Optimal Taxation when Human Capital is Endogenous," Working Paper.

[50] Karabarbounis, M. (2012), “Heterogeneity in Labor Supply Elasticity and Optimal Taxation," Working Paper.

[51] Katz, L. and K. Murphy (1992), “Changes in Relative Wages, 1963-1987: Supply and Demand Factors," Quarterly Journal of Economics, 107, 35-78.

[52] Keane, M. and K. Wolpin (2001), "The Effect of Parental Transfers and Borrowing Constraints on Educational Attainment," International Economic Review, 42, 10511103.

[53] Kindermann, F. (2012), "Welfare Effects of Privatizing Public Education When Human Capital Investments Are Risky," Journal of Human Capital, 6, 87-123.

[54] Krueger, D. and A. Ludwig (2013), “Optimal Progressive Labor Income Taxation and Education Subsidies When Education Decisions and Intergenerational Transfers are Endogenous," American Economic Review, 103, 496-501.

[55] Lochner, L. and A. Monge (2011), "Credit Constraints in Education," forthcoming, Annual Review of Economics.

[56] Ludwig, A., T. Schelkle and E. Vogel (2012), “Demographic Change, Human Capital and Welfare," Review of Economic Dynamics, 15(1), 94-107.

[57] Mendoza, E., A. Razin and L. Tesar (1994), "Effective Tax Rates in Macroeconomics: Cross-Country Estimates on Factor Income and Consumption," Journal of Monetary Economics, 34, 297-323. 
[58] Mirrless, J. (1971), "An Exploration in the Theory of Optimum Income Taxation," Review of Economic Studies, 38, 175-208.

[59] Rothschild, C. and F. Scheuer (2013), "Redistributive Taxation in the Roy Model," Quarterly Journal of Economics, 128, 623-668.

[60] Saez, E. and S. Stantcheva (2013), "Optimal Tax Theory with Endogenous Social Marginal Welfare Weights," Working paper, UC Berkeley.

[61] Stiglitz, J. (1982), "Self-Selection and Pareto Efficient Taxation," Journal of Public Economics, 17, 213-230.

[62] Weinzierl, M. (2011), “The Surprising Power of Age-Dependent Taxes," Review of Economic Studies, 78, 1-29.

[63] Weinzierl, M. (2012) “The Promise of Positive Optimal Taxation: A Generalized Theory Calibrated to Survey Evidence on Normative Preferences Explains Puzzling Features of Policy," NBER Working Paper 18599.

[64] Winter, C. (2014) "Accounting for the Changing Role of Family Income in Determining College Entry," The Scandinavian Journal of Economics, $116,909-963$ 
FIGURES

Table 1: Estimates for Earnings Process and Markov Chain for Wages

\begin{tabular}{l|ccc|ccc}
\hline \hline & \multicolumn{3}{|c|}{ Estimates } & \multicolumn{3}{c}{ Markov Chain } \\
\hline Group & $\varrho$ & $\sigma_{\eta}^{2}$ & $\sigma_{\alpha}^{2}$ & $\pi_{s}$ & $\sigma_{s}$ & $\mathcal{E}_{s}$ \\
\hline College & 0.969 & 0.0100 & 0.0474 & 0.941 & 0.191 & $\{0.811,1.188\}$ \\
Non-College & 0.928 & 0.0192 & 0.0644 & 0.871 & 0.250 & $\{0.755,1.244\}$ \\
\hline \hline
\end{tabular}

Note: The left part of this table summarizes the estimates of the AR(1) stochastic earnings process from the PSID, separately for unskilled and skilled individuals. The right part summarizes the corresponding discretized earnings process used in the model economy. 
Table 2: Calibration

\begin{tabular}{|c|c|c|}
\hline Parameter & Interpretation & Value \\
\hline \multicolumn{3}{|c|}{ Exogenously Calibrated Parameters } \\
\hline \multicolumn{3}{|c|}{ Population } \\
\hline$j_{a}$ & Age at $\mathrm{HH}$ form. (age 18) & 4 \\
\hline$j_{c}$ & Age, coll. compl. (age 21) & 5 \\
\hline$j_{f}$ & Fertility Age (age 30) & 7 \\
\hline$j_{r}$ & Retirement Age (age 66) & 16 \\
\hline$J$ & Max. Lifetime (age bin 98-101) & 24 \\
\hline$\chi$ & Population Growth Rate & 1.008 \\
\hline$\left\{\varphi_{j}\right\}$ & Survival Probabilities & Life Tables SSA \\
\hline \multicolumn{3}{|c|}{ Labor Productivity } \\
\hline$\left\{\varepsilon_{j, s}\right\}$ & Age Profile & Estimates (PSID) \\
\hline $\mathcal{E}_{S}$ and $\pi_{S}\left(\eta^{\prime} \mid \eta\right)$ & Stochastic Part of Wages & Estimates (PSID) \\
\hline \multicolumn{3}{|c|}{ Preferences } \\
\hline $\bar{\sigma}$ & Coef. of Rel. Risk Aversion $=2$ & 4 \\
\hline$\zeta$ & Equivalence Scale & 0.3 \\
\hline \multicolumn{3}{|c|}{ Technology } \\
\hline$\alpha$ & Capital Share & $33.3 \%$ \\
\hline$\delta$ & Depreciation & $7.55 \%$ \\
\hline$\rho$ & Subst. Elasticity $(1 /(1-\rho)) \in\{1.4, \infty\}$ & $\{0.285,1\}$ \\
\hline \multicolumn{3}{|c|}{ Ability and Education } \\
\hline$\phi$ & Tightness of Borrowing Constraint & $75.0 \%$ \\
\hline \multicolumn{3}{|c|}{ Government Policy } \\
\hline$\theta$ & Public Education Subsidy & $38.8 \%$ \\
\hline$\theta_{p}$ & Private Education Subsidy & $16.6 \%$ \\
\hline$\tau_{c}$ & Consumption Tax Rate & $5.0 \%$ \\
\hline$\tau_{k}$ & Capital Income Tax Rate & $28.3 \%$ \\
\hline$b$ & Debt-GDP Ratio & $60.0 \%$ \\
\hline$g y$ & Gov. Cons to GDP Ratio & $17.0 \%$ \\
\hline$\tau^{p}$ & Social Security Payroll Tax & $12.4 \%$ \\
\hline \multicolumn{3}{|c|}{ Parameters Calibrated in Equilibrium (Targets in Brackets) } \\
\hline \multicolumn{3}{|c|}{ Preferences } \\
\hline$\beta$ & Time Discount Rate $(K / Y)$ & 0.988 \\
\hline$v$ & Altruism Parameter (Avg. Transfers) & 0.482 \\
\hline$\mu$ & Leisure Share (Fraction of $h$ worked) & 0.374 \\
\hline \multicolumn{3}{|c|}{ Ability and Education } \\
\hline$\varepsilon \equiv \frac{{ }^{\epsilon} j_{c, c}}{\epsilon_{j_{c}, n}}$ & Relative Productivity at age $j_{\mathcal{c}}($ College Wage Premium, 1.8$)$ & 1.03 \\
\hline$v \quad$ & Probability to draw $\gamma_{h}, \pi\left(\gamma=\gamma^{h} \mid e, s=n\right)=b \cdot e$ (College Wage Premium for Marginal HH) & 0.5 \\
\hline$\lambda$ & Time Costs of College (College Completion) & 1.351 \\
\hline$\sigma_{e}$ & Std. Dev of $e$ (Distribution Coverage $90 \%$ ) & 0.266 \\
\hline$\kappa$ & Resource Cost of Coll. (Spend. on Tert. Educ.) & 0.203 \\
\hline$\vartheta_{1 s}$ & (s-specific variance of fixed effect) & {$[0.338,0.243]$} \\
\hline$x$ & $\mu(e)$-shifter for $\gamma^{h}$ (Intergenerational Earnings Persistence of 0.4) & 0.134 \\
\hline$\zeta$ & $\mu(e)$-shifter for $s_{p}=c$ (Intergenerational Education Persistence) & 0.057 \\
\hline \multicolumn{3}{|c|}{ Government Policy } \\
\hline$\tau_{l}$ & Labor Income Tax Rate (Budget Bal.) & $27.5 \%$ \\
\hline$d$ & Tax Deduction Rate (Median Rate of 35\%) & $27.1 \%$ \\
\hline
\end{tabular}

Note: Table summarizes the parameter values for the benchmark economy, including the empirical targets the parameters are calibrated to. 
Table 3: Benchmark Results: Optimal Policies and Macroeconomic Aggregates in the Long Run

\begin{tabular}{|c|c|c|c|c|c|}
\hline & & \multicolumn{2}{|c|}{ Trans. Dynamics } & \multicolumn{2}{|c|}{ Steady State } \\
\hline Var. & Status Quo & Opt. Pol. & Change & Opt. Pol. & Change \\
\hline$\tau_{l}$ & $27.55 \%$ & $21.9 \%$ & $-5.69 \% p$ & $26.03 \%$ & $-1.53 \% p$ \\
\hline$d$ & $27.1 \%$ & $6 \%$ & $-21.1 \% \mathrm{p}$ & $10 \%$ & $-17.1 \% \mathrm{p}$ \\
\hline$\theta$ & $38.8 \%$ & $150 \%$ & $111.2 \% \mathrm{p}$ & $200 \%$ & $161.2 \% \mathrm{p}$ \\
\hline Z & 0.0714 & 0.0171 & $-76.05 \%$ & 0.0281 & $-60.57 \%$ \\
\hline$\tau_{l} \cdot Z$ & 0.0197 & 0.0037 & $-80.98 \%$ & 0.0073 & $-62.76 \%$ \\
\hline$Y / N$ & 0.2633 & 0.2847 & $8.15 \%$ & 0.2813 & $6.85 \%$ \\
\hline$B / Y$ & $60.16 \%$ & $79.81 \%$ & $19.65 \%$ p & $60.16 \%$ & $0 \% \mathrm{p}$ \\
\hline$K / N$ & 0.1731 & 0.1899 & $9.73 \%$ & 0.1866 & $7.8 \%$ \\
\hline$L / N$ & 2.2097 & 2.3782 & $7.63 \%$ & 2.3508 & $6.39 \%$ \\
\hline$K / L$ & 0.1097 & 0.1118 & $1.95 \%$ & 0.1111 & $1.33 \%$ \\
\hline$w$ & 0.1118 & 0.1123 & $0.49 \%$ & 0.1122 & $0.44 \%$ \\
\hline$\frac{w_{c}}{w_{n}}$ & 0.3801 & 0.2946 & $-22.49 \%$ & 0.2732 & $-28.12 \%$ \\
\hline$r$ & $5.37 \%$ & $5.26 \%$ & $-0.11 \% p$ & $5.27 \%$ & $-0.09 \% \mathrm{p}$ \\
\hline hours & 0.326 & 0.3392 & $1.32 \%$ & 0.3329 & $0.7 \%$ \\
\hline$C / N$ & 0.1628 & 0.1795 & $10.28 \%$ & 0.1731 & $6.32 \%$ \\
\hline Trans/Assets & $1.15 \%$ & $1.01 \%$ & $-0.15 \% \mathrm{p}$ & $0.78 \%$ & $-0.37 \% \mathrm{p}$ \\
\hline college share & $43.89 \%$ & $54.37 \%$ & $10.48 \% \mathrm{p}$ & $58.57 \%$ & $14.68 \% \mathrm{p}$ \\
\hline $\operatorname{Gini}(c)$ & 0.235 & 0.2078 & $-2.72 p$ & 0.1996 & $-3.54 p$ \\
\hline $\operatorname{Gini}(h)$ & 0.12 & 0.1266 & $0.66 \mathrm{p}$ & 0.1243 & $0.43 p$ \\
\hline Gini(a) & 0.5558 & 0.5369 & $-1.89 p$ & 0.5493 & $-0.65 p$ \\
\hline$C E V$ & & & $3.4652 \%$ & & $2.7569 \%$ \\
\hline
\end{tabular}

Note: This table summarizes optimal policies and the long-run change in macroeconomic aggregates, distributions and welfare for $\rho=0.285$ (an elasticity of substitution between unskilled and skilled labor of 1.4). 
Table 4: Optimal Policies and Macroeconomic Aggregates in the Long Run: Perfect Substitutes

\begin{tabular}{l||r|rr|rr}
\hline \hline & & \multicolumn{2}{|c|}{ Trans. Dynamics } & \multicolumn{2}{|c}{ Steady State } \\
\hline Var. & Status Quo & Opt. Pol. & Change & Opt. Pol. & Change \\
\hline$\tau_{l}$ & $27.55 \%$ & $22.9 \%$ & $-4.68 \% \mathrm{p}$ & $36.98 \%$ & $9.43 \% \mathrm{p}$ \\
$d$ & $27.1 \%$ & $10 \%$ & $-17.1 \% \mathrm{p}$ & $31 \%$ & $3.9 \% \mathrm{p}$ \\
$\theta$ & $38.8 \%$ & $120 \%$ & $81.2 \% \mathrm{p}$ & $170 \%$ & $131.2 \% \mathrm{p}$ \\
$Z$ & 0.0714 & 0.0303 & $-57.56 \%$ & 0.0866 & $21.38 \%$ \\
$\tau_{l} \cdot Z$ & 0.0197 & 0.0069 & $-64.75 \%$ & 0.032 & $62.94 \%$ \\
\hline$Y / N$ & 0.2633 & 0.3032 & $15.15 \%$ & 0.2794 & $6.12 \%$ \\
$B / Y$ & $60.16 \%$ & $96.95 \%$ & $36.79 \% \mathrm{p}$ & $60.16 \%$ & $0 \% \mathrm{p}$ \\
$K / N$ & 0.1731 & 0.1951 & $12.74 \%$ & 0.1781 & $2.92 \%$ \\
$L / N$ & 0.4532 & 0.5259 & $16.06 \%$ & 0.4882 & $7.73 \%$ \\
$K / L$ & 0.5346 & 0.5194 & $-2.86 \%$ & 0.5108 & $-4.47 \%$ \\
$w$ & 0.5449 & 0.5407 & $-0.78 \%$ & 0.5368 & $-1.5 \%$ \\
$w_{c}$ & 1 & 1 & $0 \%$ & & $0 \%$ \\
$w_{n}$ & $5.37 \%$ & $5.54 \%$ & $0.17 \% \mathrm{p}$ & $5.7 \%$ & $0.33 \% \mathrm{p}$ \\
hours & 0.326 & 0.3287 & $0.27 \%$ & 0.2985 & $-2.75 \%$ \\
$C / N$ & 0.1628 & 0.1934 & $18.82 \%$ & 0.1717 & $5.47 \%$ \\
Trans / Assets & $1.15 \%$ & $1.39 \%$ & $0.23 \% \mathrm{p}$ & $0.78 \%$ & $-0.37 \% \mathrm{p}$ \\
college share & $43.89 \%$ & $75.79 \%$ & $31.9 \% \mathrm{p}$ & $82.07 \%$ & $38.18 \% \mathrm{p}$ \\
\hline Gini $(c)$ & 0.235 & 0.2186 & $-1.64 \mathrm{p}$ & 0.1987 & $-3.62 \mathrm{p}$ \\
Gini $(h)$ & 0.12 & 0.1283 & $0.83 \mathrm{p}$ & 0.1176 & $-0.24 \mathrm{p}$ \\
Gini $(a)$ & 0.5558 & 0.5203 & $-3.55 \mathrm{p}$ & 0.5336 & $-2.22 \mathrm{p}$ \\
\hline CEV & & & $1.6565 \%$ & & $2.6126 \%$ \\
\hline \hline
\end{tabular}

Note: This table summarizes optimal policies and the long-run change in macroeconomic aggregates, distributions and welfare for $\rho=1$ (in which case unskilled and skilled labor are perfect substitutes in production). 
Table 5: Welfare Consequences for Different Policy Combinations: Perfect Substitutes

\begin{tabular}{cccc}
\hline \hline & $d=0.1, \theta=1.2$ & $d=0.27, \theta=1.2$ & $d=0.31, \theta=1.7$ \\
\hline$C E V$ & $1.6565 \%$ & $0.0981 \%$ & $-2.8027 \%$ \\
\hline \hline
\end{tabular}

Note: This table displays the welfare gains, relative to the status quo, from transitions induced by different policy configurations in the perfect substitution case. 
Table 6: Final Steady State: Decomposition

\begin{tabular}{l|ccc|ccc}
\hline \hline & \multicolumn{3}{|c|}{ Perfect Substitutes $\rho=1$} & \multicolumn{3}{c}{ Imperfect Substitutes $\rho=0.28$} \\
\hline Var. & Baseline & Const. $d$ & Const. $\theta$ & Baseline & Const. $d$ & Const. $\theta$ \\
\hline$\tau_{l}$ & $36.9 \%$ & $35.0 \%$ & $29.3 \%$ & $26.0 \%$ & $32.5 \%$ & $29.3 \%$ \\
$d$ & $31 \%$ & $27.1 \%$ & $31 \%$ & $10 \%$ & $27.1 \%$ & $31 \%$ \\
$\theta$ & $170 \%$ & $175 \%$ & $38.8 \%$ & $200 \%$ & $175 \%$ & $38.8 \%$ \\
$Z$ & 0.086 & 0.077 & 0.08 & 0.028 & 0.071 & 0.080 \\
$\tau_{l} \cdot Z$ & 0.032 & 0.027 & 0.023 & 0.007 & 0.023 & 0.023 \\
\hline$C E V$ & $2.612 \%$ & $2.508 \%$ & $0.167 \%$ & $2.756 \%$ & $2.413 \%$ & $0.130 \%$ \\
\hline \hline
\end{tabular}

Note: This table displays the steady state welfare gains for different policy configurations. 


\section{FIGURES}

Figure 1: Time Line in the Model

\section{Model: Life Cycle of Households}

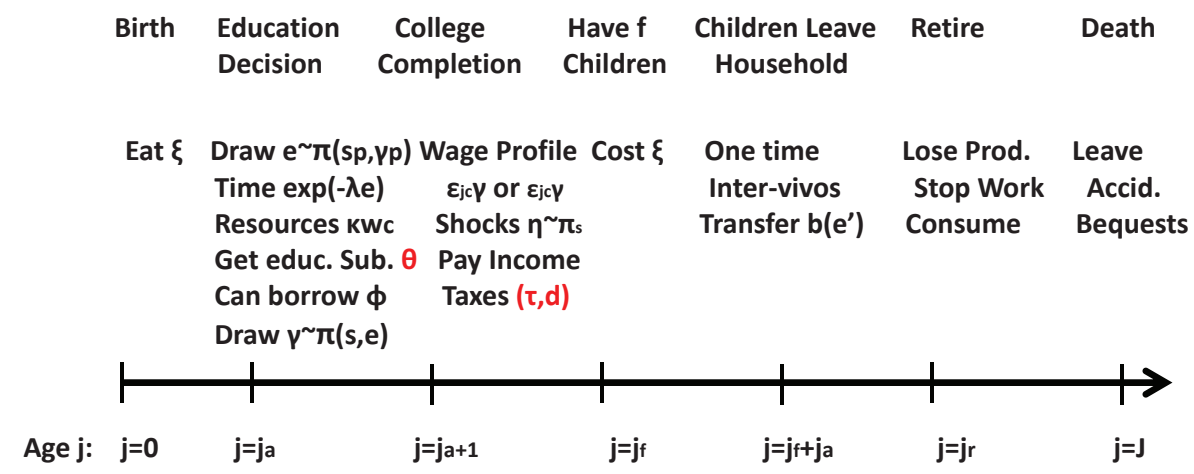

Note: This figure summarize the key life cycle events and decisions. 
Figure 2: Fraction of Households Deciding to Go to College

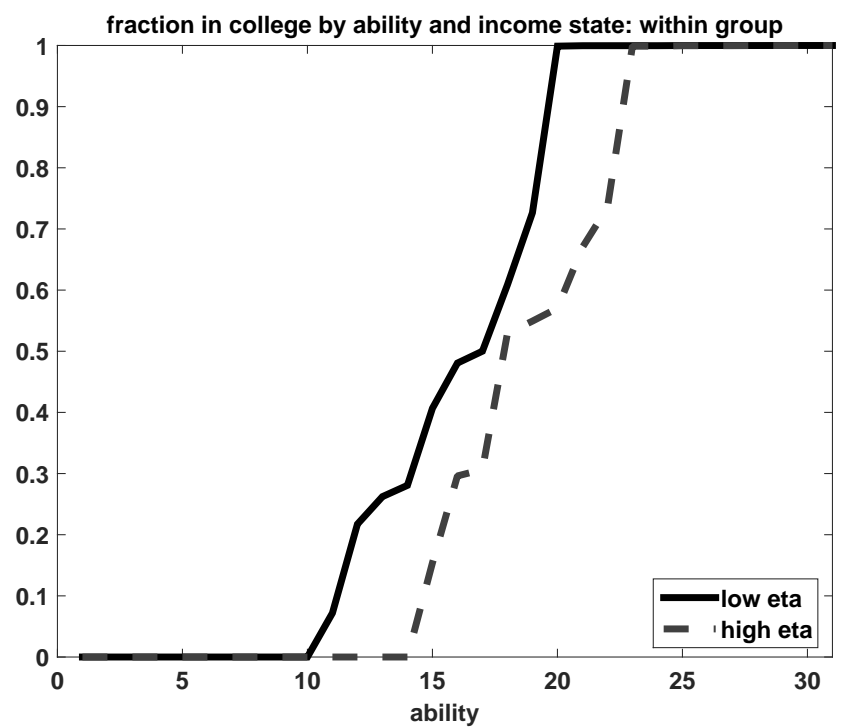

Note: This figure plots the share of households in college age going to college, as function of their ability $e \in\left\{e_{1}, \ldots, e_{31}\right\}$. Each line represents an income shock $\eta \in\left\{\eta_{l}, \eta_{h}\right\}$. 
Figure 3: College Decision by Initial Assets

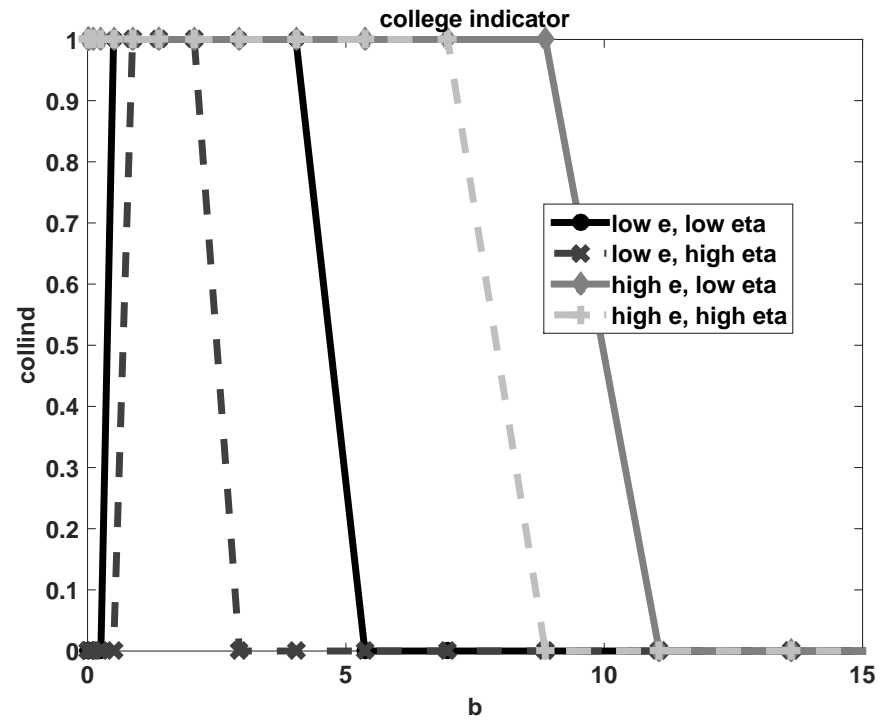

Note: This figure plots the optimal college decision rule against initial wealth $b$. A value of 0 stands for not attending college, a value of 1 for going to college. Each line represents an income shock $\eta \in\left\{\eta_{l}, \eta_{h}\right\}$ and ability level $e$. The low (high) ability group is group 17 (25) out of 31 groups. 
Figure 4: Evolution of Macroeconomic Aggregates: Imperfect Substitutes
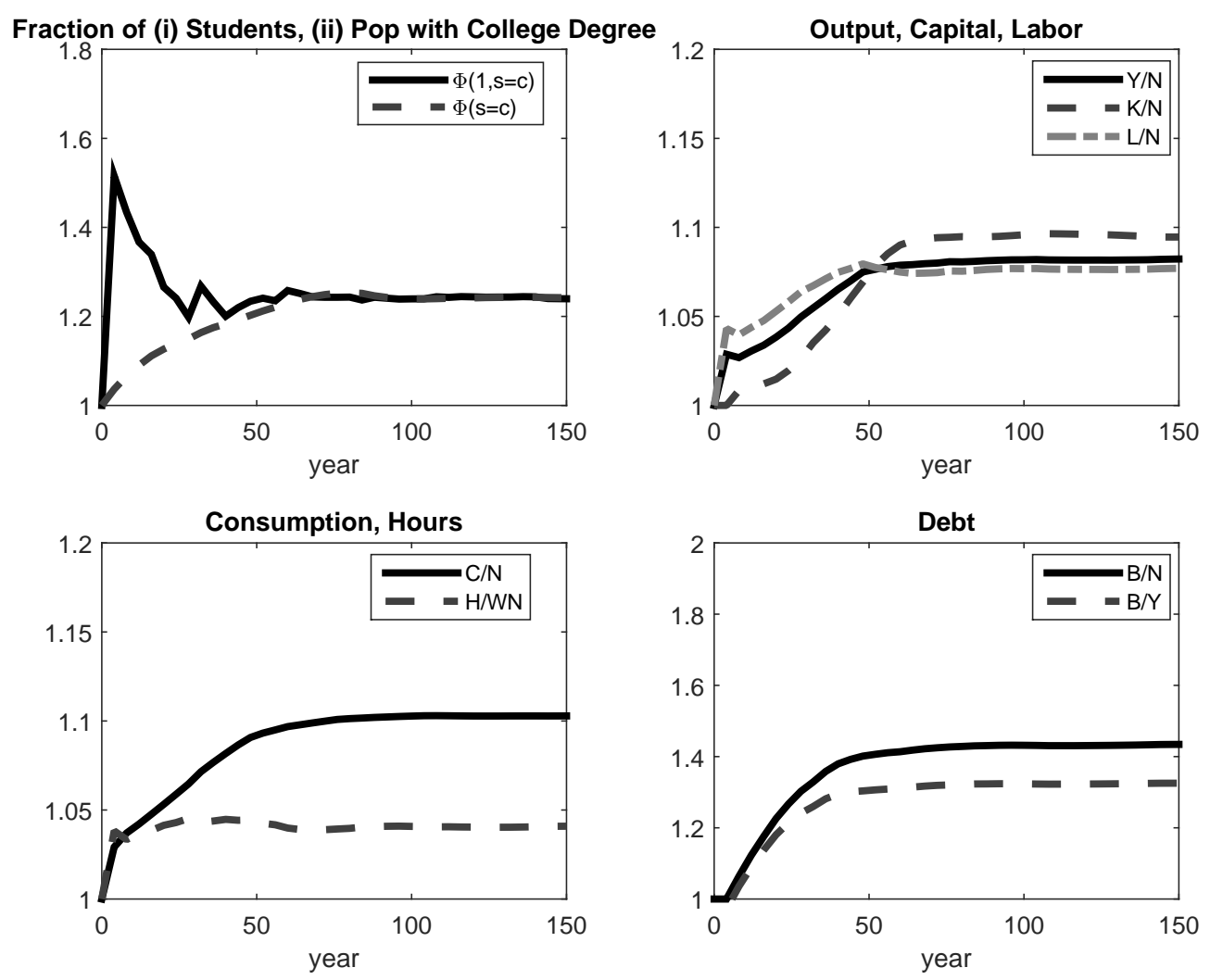

Note: this figure plots the transition paths of key macroeconomic aggregates aginst time. The elasticity of substitution between unskilled and skilled labor is 1.4 ( $\rho=$ $0.285)$ 
Figure 5: Wages of College and Non-College Households: Imperfect Substitutes

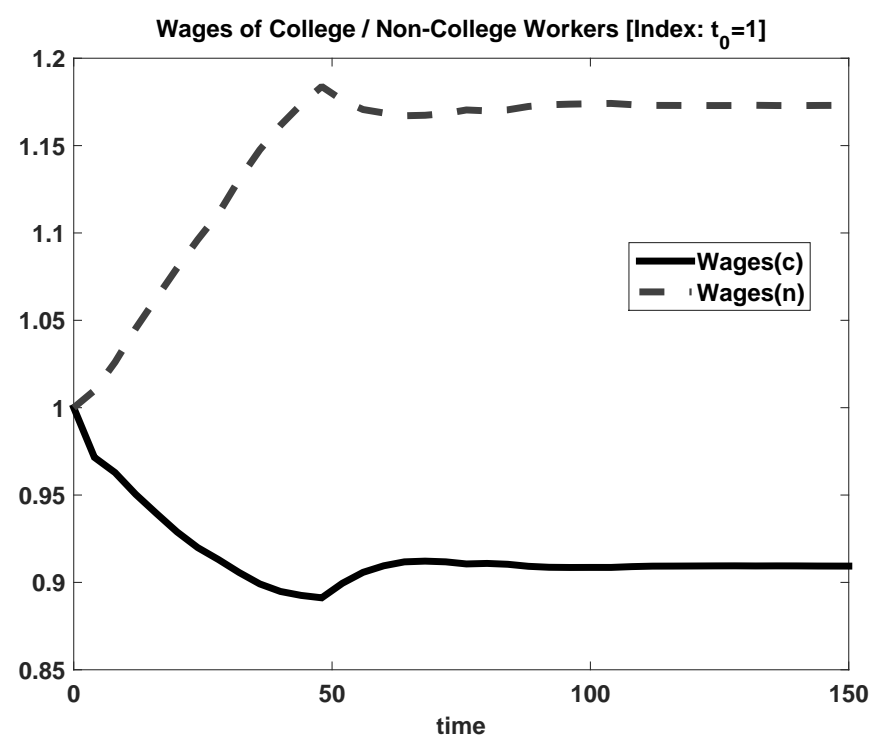

Note: this figure plots the transition paths of (average) wages for college-educated and unskilled workers aginst time. The elasticity of substitution between unskilled and skilled labor is $1.4(\rho=0.285)$ 
Figure 6: Evolution of Macroeconomic Aggregates: Perfect Substitutes
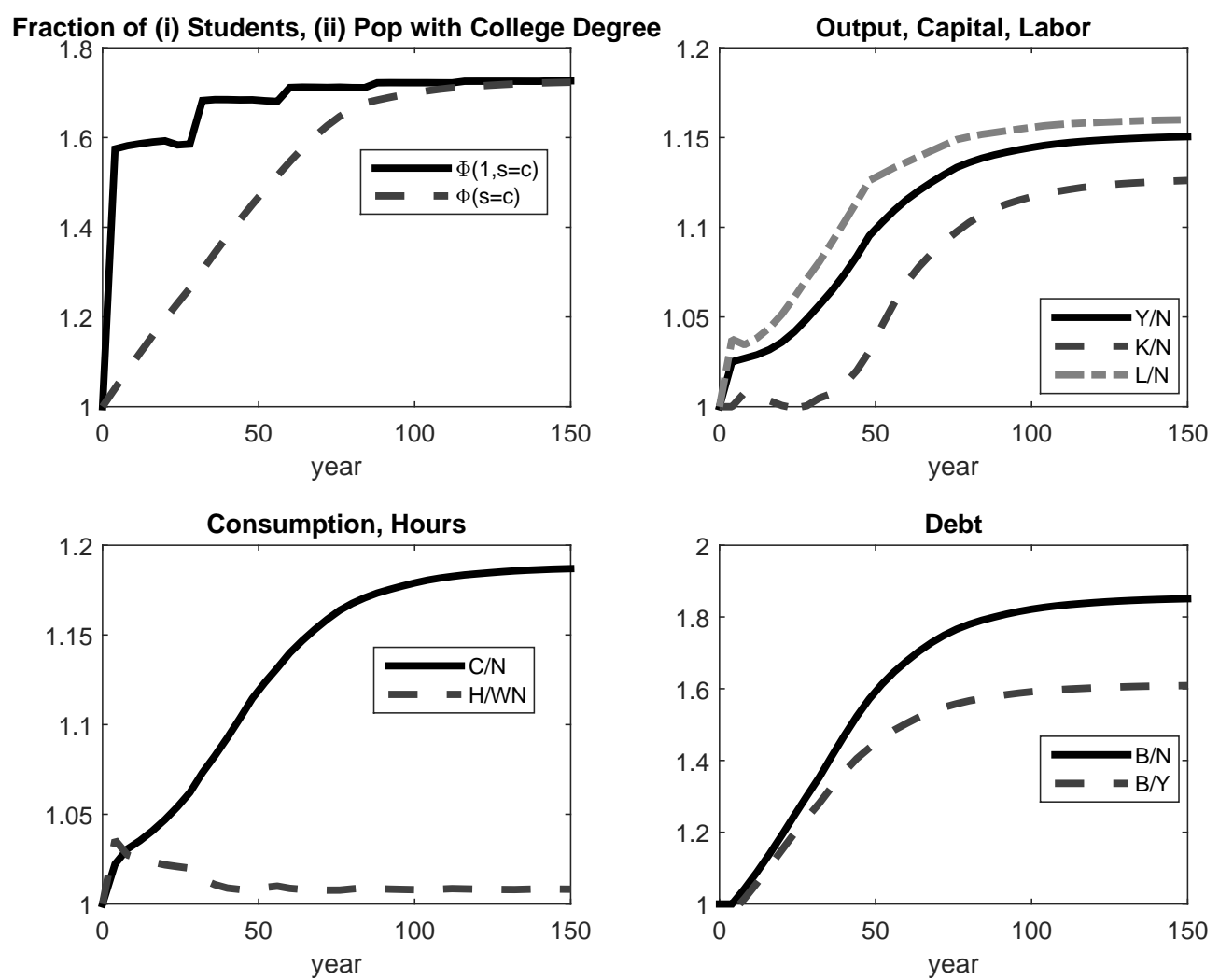

Note: this figure plots the transition paths of key macroeconomic aggregates aginst time. Unskilled and skilled labor are prefect substitutes $(\rho=1)$ 
Figure 7: Evolution of Per-Capita Consumption: Perfect Substitutes

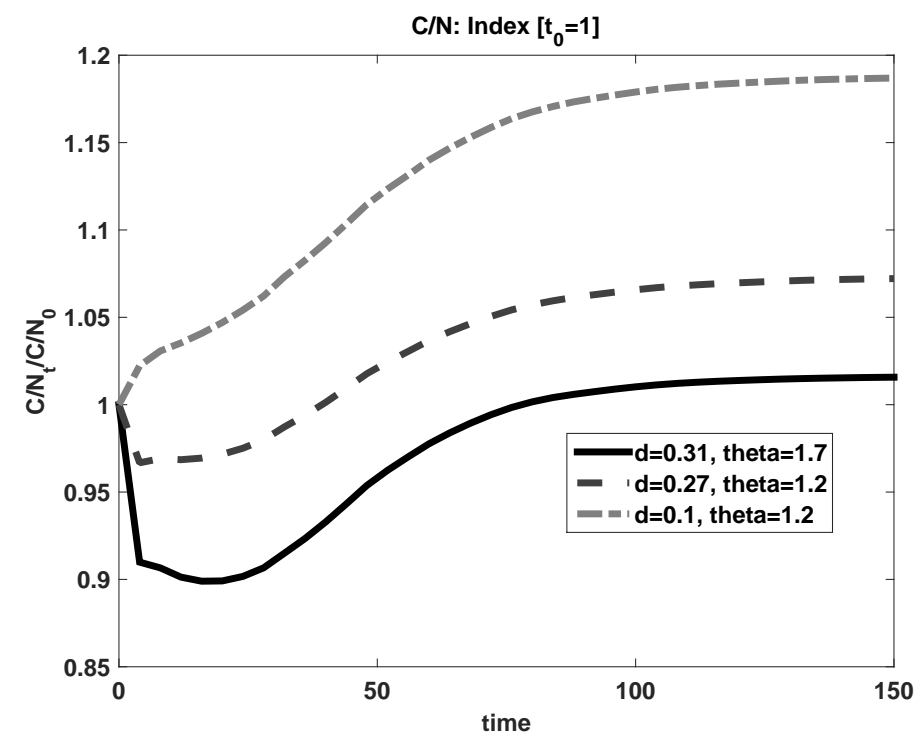

Note: this figure plots the transition paths of per capita consumption under different policy configurations. The elasticity of substitution between unskilled and skilled labor is $1.4(\rho=0.285)$. 